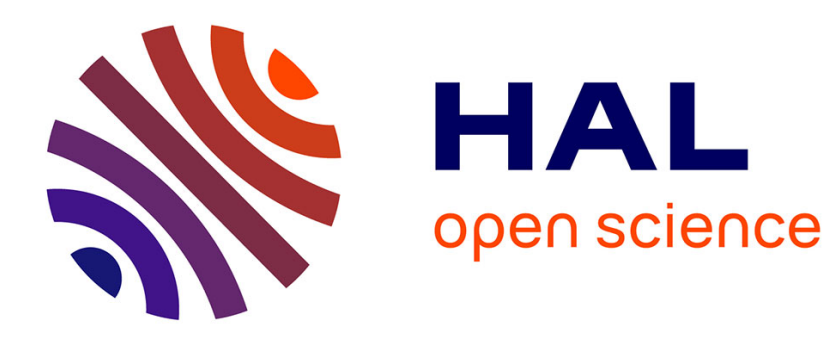

\title{
Nouvelles scènes figurant des souveraines ptolémaïques officiant seules
}

Laetitia Martzolff

\section{To cite this version:}

Laetitia Martzolff. Nouvelles scènes figurant des souveraines ptolémaïques officiant seules. Zeitschrift für ägyptische Sprache und Altertumskunde, 2009, 136, pp.37-55. halshs-00579826

\section{HAL Id: halshs-00579826 \\ https://shs.hal.science/halshs-00579826}

Submitted on 25 Mar 2011

HAL is a multi-disciplinary open access archive for the deposit and dissemination of scientific research documents, whether they are published or not. The documents may come from teaching and research institutions in France or abroad, or from public or private research centers.
L'archive ouverte pluridisciplinaire $\mathbf{H A L}$, est destinée au dépôt et à la diffusion de documents scientifiques de niveau recherche, publiés ou non, émanant des établissements d'enseignement et de recherche français ou étrangers, des laboratoires publics ou privés. 


\section{Nouvelles scènes figurant des souveraines ptolémaïques officiant seules ${ }^{1}$}

Au cours de ces dernières années, la question de la représentation de la souveraine ptolémaïque sur les parois des temples a été abordée à plusieurs reprises, surtout lorsqu’elle officiait seule ${ }^{2}$. En l'an 2000, dans un article consacré à l'étude d'un bloc d'une collection privée ayant sans doute présenté une reine comme seule officiante, Ol. Perdu dresse une liste de 38 attestations datées de la période ptolémaïque dans lesquelles la reine fait une offrande à une ou des divinités ${ }^{3}$. La première attestation, qu'il identifie dans le mammisi du temple de Philae, est datée par l'auteur du règne de Ptolémée III Evergète I, les dernières de celui de Cléopâtre VII.

Deux occurrences retiennent particulièrement son attention. Sculptées en façade du spéos ptolémaïque d’Elkab, les deux représentations placées en correspondance montrent Cléopâtre III agitant des sistres devant la déesse locale Nekhbet. Contrairement aux autres attestations, la reine n’est pas mise en correspondance, dans la scène associée de la série liturgique opposée, avec une figure masculine, composante royale masculine, mais avec sa propre image. L'auteur estime que la nature féminine de la divinité bénéficiaire a pu justifier la figuration double de la reine, la volonté du décorateur étant d’accentuer la coloration féminine de la représentation ${ }^{4}$.

Par la suite, ces attestations ont été examinées par deux autres chercheurs, G. Hölbl et M. Minas. Le premier estime qu’à Elkab, la présence de la reine se justifie d'abord par le fait qu'elle a occupé une place importante au sein du pouvoir politique puisqu'associée au règne de son fils Ptolémée IX Sôter II $^{5}$. Quant à M. Minas, elle rejoint G. Hölbl dans sa justification

\footnotetext{
${ }^{1}$ Qu'il me soit permis de remercier Cl. Traunecker, J.F. Quack et M. Minas-Nerpel pour leurs réflexions qui ont permis de faire considérablement évoluer ce travail ainsi que L. Schmitt et M. Meyer qui s'emploient avec toujours autant de patience et de gentillesse à la relecture de mes épreuves.

${ }^{2}$ La primeur des études revient à J. Quaegebeur qui s’est intéressé à la question de la représentation des souveraines en particulier dans le cadre de ses travaux liés à la divinisation d’Arsinoé II. Voir J. QuAEGEBEUR, « Reines ptolémaïques et traditions égyptiennes », dans H. Maehler, V.M. Strocka (éd.), Das ptolemäische Ägypten. Akten des internationalen Symposions 27.-29. September 1976 in Berlin, Mayence, 1978, p. 245-246. Sur la question de la divinisation d'Arsinoé II, ibidem, « Ptolémée II en adoration devant Arsinoé II divinisée », BIFAO 69, 1971, p. 191-217 et « Documents concerning a cult of Arsinoe Philadelphos at Memphis », JNES 30, 1971, p. 239-270.

${ }^{3}$ Ol. PERDU, « Souvenir d’une reine ptolémaïque officiant seule », ZÄS 127, 2000, p. 141-152.

${ }^{4}$ Ol. PERDU, « Souvenir d’une reine ptolémaïque officiant seule », ZÄS 127, 2000, p. 151.

${ }^{5}$ G. HöLBL, « Ptolemäische Königin und weiblicher Pharao », dans N. Bonacasa, A.M. Donadoni Roveri, S. Aiose, P. Minà (éd.), Faraoni come dei, Tolemei come faraoni. Atti del V Congresso Internazionale ItaloEgiziano, Torino, Archivo di Stato - 8-12 dicembre 2001, Torino, Palermo, 2003, p. 93-94.
} 
des représentations et note également que la reine, bien que figurée seule dans les deux tableaux, n'est pas affranchie totalement de toute tutelle masculine puisque les cartouches de Ptolémée IX Sôter II étaient sculptées au niveau de la frise et que le souverain était l’officiant des scènes sculptées sur la porte d'accès à la cour ${ }^{6}$.

Nous nous proposons, dans cette contribution, d'étudier deux autres cas de figure provenant des temples de Philae et de Tôd mettant en correspondance deux tableaux dans lesquels une souveraine ptolémaïque officie seule. Ces deux nouvelles attestations, auxquelles doivent être ajoutées quatre scènes du mammisi d'Erment, ôtent à l'exemple d'Elkab son statut d'unicum et permettent de mettre en évidence l'existence de deux situations distinctes dans lesquelles la souveraine agit comme seule officiante. Dans la très grande majorité des cas, les reines agissent devant une ou des divinités et sont associées, dans le tableau correspondant de la série liturgique opposée, à la composante mâle à laquelle leur règne est associé, qu'il s'agisse d'un père, d'un fils ou d'un époux. À ces exemples peuvent être opposés ceux d’Elkab, Philae et Tôd qui associent deux scènes en miroir ayant pour seule officiante la reine.

Après un rappel des principales caractéristiques des tableaux d’Elkab, nous présenterons les scènes de Philae et de Tôd avant de revenir brièvement sur les principales caractéristiques des figurations d'Erment. Cela permettra de procéder à une comparaison des trois ensembles afin de mettre en évidence les particularités de ces représentations et de tenter d’identifier les raisons qui en ont justifié la gravure.

\section{A. Rappel : les représentations du spéos ptolémaïque d'Elkab (fiq. 1-2)}

Le spéos ptolémaïque d’Elkab se trouve à l'entrée du ouadi Hellal, en bordure de désert $^{7}$. Les scènes qui nous intéressent sont sculptées en façade du sanctuaire, de part et d'autre de la porte ${ }^{8}$. Extrêmement mal préservées, elles ne conservent aujourd’hui plus que la

\footnotetext{
${ }^{6}$ Ph. DerChain, Elkab I. Les monuments religieux à l'entrée de l'Ouady Hellal, Bruxelles, 1971, p. 37 et M. MiNAS, « Macht und Ohnmacht. Die Repräsentation ptolemäischer Königinnen in ägyptischen Tempel », APF 51, 2005, p. 143-144.

${ }^{7}$ F. Depuydt, S. HendrickX, D. HuYGE, Elkab IV. Topographie, Bruxelles, 1989, plan I, n57.

${ }^{8} \mathrm{Ph}$. Derchain, Elkab I. Les monuments religieux à l'entrée de l'Ouady Hellal, Bruxelles, 1971, pl. 8 et 14. Nous avons repris la dénomination proposée par Ph. Derchain. Par sanctuaire nous entendons donc l'espace creusé dans la roche.
} 
figure de la souveraine, Cléopâtre III, agitant des sistres devant la divinité locale, Nekhbet, dont seuls les nom et épithètes sont encore visibles.

Le titre de la scène du tableau ouest est totalement perdu à l'inverse de celui de la scène est dans laquelle la reine s’adresse à la divinité en ces termes : «Salut, œil de Râ, maîtresse des sistres, Dorée, souveraine des Deux Pays... ... celle dont les yeux sont rouges (de colère) lorsqu'elle exerce sa puissance contre des millions, en fureur, dame de terreur mais qui s'apaise... ... comme Râ, à jamais. ${ }^{9}$ ". Nekhbet est désignée comme une forme apaisée de la Lointaine et est identifiée à la Dorée, c'est-à-dire Hathor. Ce contexte justifie pleinement l'action de la reine qui agite les sistres, acte d'apaisement par excellence ${ }^{10}$, et s'accorde parfaitement avec la localisation topographique du spéos, placé en bordure du désert, en position idéale pour accueillir la Lointaine lorsqu’elle revient en territoire civilisé.

Dans l'étude qu'il a consacrée à l'édifice, Ph. Derchain avait noté la titulature particulière de la reine, titulature qu'il qualifiait de "virile » ${ }^{11}$. En effet, Cléopâtre III est «Horus-Râ, taureau vigoureux, Horus femelle, maîtresse des deux terres ». Cette titulature, intégrée à ces représentations où la souveraine est seule représentée, est assurément pour lui « un indice de la réalité de son pouvoir, qu'elle exerce donc en titre » ${ }^{12}$. La reine est également désignée, dans la colonne marginale divine du tableau ouest, comme « la fille de roi, l'épouse de roi, la mère de roi, la souveraine, la maîtresse des deux terres ḍCléopâtre)| ${ }^{13}$. Ces épithètes sortent la reine de son isolement et la situent, pour la seule et unique fois pour l'ensemble des textes des deux tableaux, par rapport à d'autres protagonistes royaux de sexe masculin : elle est la fille du roi (Ptolémée VI Philométor), l’épouse du roi (Ptolémée VIII Evergète II) et la mère du roi (Ptolémée IX Sôter II). Cette mention accorde une justification plus grande encore à la représentation de la reine qui est légitimée par ce ‘pedigree’ royal. Bien que seule officiante figurée dans les deux tableaux de façade, il ne faut pas oublier, comme l'a souligné justement M. Minas, qu'elle était bien associée à son fils Ptolémée IX Sôter $\mathrm{II}^{14}$ dont les noms, inscrits au niveau de la frise, alternent avec des visages d'Hathor. C'est ce même roi qui officiait dans les scènes adjacentes de la porte, aujourd'hui détruite, mais dont on peut deviner

\footnotetext{
${ }^{9}$ Traduction Ph. DERCHAIN, op. cit., p. $49^{\mathrm{a}}$.

${ }^{10}$ C. ZIEGLER, « Sistrum », LÄ V, 1984, col. 960 et J.-Cl. GoyON, Le rituel du shtp Shmt au changement de cycle annuel, BdE 141, 2006, p. 86.

${ }^{11}$ Ph. Derchain, op. cit., p. $49^{\mathrm{b}}$ et $49^{4}$.

${ }^{12} \mathrm{Ph}$. Derchain, op. cit., p. $49^{4}$. L'auteur souligne le caractère exceptionnel de ces représentations et fait le lien avec les scènes de Kom Ombo où la reine officie seule.

${ }^{13}$ Ph. Derchain, op. cit., p. $7^{*[\mathrm{~d}]}$.

${ }^{14}$ Sur l'identification de ce roi plutôt que Ptolémée X Alexandre I, voir Ph. DERCHAIN, op. cit., p. $37^{\text {note } 1}$.
} 
l'organisation du décor à partir d'un relevé de Nestor L'Hôte et des travaux de Ph. Derchain ${ }^{15}$.

\section{B. La nouvelle documentation}

\section{Les scènes de la porte du second pylône de Philae (annexes 1-2, fiq. 3-5)}

[Datation] La porte du second pylône de Philae a été décorée sous le règne de Ptolémée VIII Evergète II et Cléopâtre II $^{16}$. La reine, qui y est figurée et mentionnée à plusieurs reprises, est systématiquement qualifiée de sœur (sn.t) et épouse (hm.t) du roi. Ces deux titres associés ne sont appliqués qu’à Cléopâtre II et sont caractéristiques de sa titulature antérieure au second mariage de Ptolémée VIII Evergète II avec Cléopâtre III ${ }^{17}$. L'ensemble du décor de la porte a donc été réalisé entre 145 av. J.-C. et 141/140 av. J.-C. ${ }^{18}$.

[Position de la reine] Cléopâtre II apparaît dans différents tableaux de la porte, mais sa position varie ${ }^{19}$. Dans les deux scènes du linteau de la face interne ainsi que dans la scène supérieure du tableau de l'embrasure (fig. $3^{\mathrm{n}^{\circ} 87-88, \mathrm{n}^{\circ} 106}$ ), elle suit passivement le roi, ne faisant que lever une main en signe de salut. En revanche, elle apparaît comme seule officiante dans

\footnotetext{
${ }^{15}$ J. VANDIER D'ABBADIE, Nestor L'Hôte, 1804-1842 : Choix de documents conservés à la Bibliothèque nationale et aux Archives du musée du Louvre, Leiden, 1963, pl. $35^{2}$ et Ph. DERCHAIN, op. cit., p. $47^{3}$ et $48^{6}$; pl. $23^{\mathrm{B}}$. L'auteur a pu retrouver deux blocs remployés qui entraient dans la composition du décor de la porte. Le premier, encastré dans la porte de la mosquée de Hellal, présente les vestiges d'une offrande d'encens à Nekhbet. Le second montre le souverain se dirigeant vers la droite, sans qu’il ait de divinité face à lui.

${ }^{16}$ Bien qu'encore inédite, la décoration peut être analysée à partir de photographies de l'expédition allemande de 1908-1910 et les fiches du Wörterbuch der ägyptischen Sprache qui offrent une copie de la quasi totalité des textes des deux scènes. Voir H. JunKER, H. SCHÄFER, Berliner Photos der preußischen Expedition 1908-1910 nach Nubien, Ägyptologisches Microfiche-Archiv 3, Wiesbaden, 1975, n²70, 272 (abrégé photo(s) Berlin). Les fiches du $W b$ sont disponibles, après s'être enregistré, sur le site du Thesaurus Linguae Aegyptiae (http://aaew.bbaw.de/tla/). Les renvois aux fiches sont effectués dans les annexes 1 et 2.

${ }^{17}$ M. ELDAMATY, « Die ptolemaïsche Königin als weiblicher Horus », article à paraître dans le volume de communications faites dans le cadre des journées internationales intitulées Ägypten zwischen innerem Zwist und äußerem Druck. Die Zeit Ptolemaios'VI. bis VIII. (Heidelberg, 17-19 septembre 2007). Après le second mariage de Ptolémée VIII Evergète II, le titre de sn.t est réservé à Cléopâtre II alors que celui de hm.t est attribué à Cléopâtre III. Je tiens à remercier l'auteur qui m’a autorisée à consulter et citer son texte avant publication.

${ }^{18}$ Sur ce mariage, qui a eu lieu entre le 8 mai 141 et le 14 janvier 140 av. J.-C., voir P.W. PESTMAN, The archive of the Theban choachytes (Second century B.C.). A survey of the demotic and greek papyri contained in the archive, StudDem 2, 1993, p. 86 ${ }^{\mathrm{b}}$ et M. MiNAS, Die hieroglyphischen Ahnenreihen der ptolemaïschen Könige. Ein Vergleich mit den Titeln der eponymen Priester in den demotischen und griechischen Papyri, AegTre 9, 2000, p. 145-147.

${ }^{19}$ Ces variations de positionnement ne sont pas le fait de phases successives de décoration. L'analyse du décor de la porte ne permettant pas de mettre en évidence une interruption dans les travaux, il faut donc admettre que l'ensemble du décor de la porte a été réalisé en une seule fois.
} 
la paire de scènes supérieures des montants de la face extérieure (fig. $3^{\mathrm{n}^{\circ} 77-78}$, fig. 4-5). Tous les autres tableaux (linteau et montants) figurent Ptolémée VIII Evergète II comme exécutant des rites.

[Titres et noms de la reine] Dans les deux scènes, Cléopâtre II est identifiée par deux cartouches, mais seul l'un d'entre eux renvoie directement à sa personne. Le second, qui présente le nom de naissance de son époux, n’est mentionné que pour préciser le statut de la reine par rapport à la composante masculine régnante. Elle est la souveraine, la maîtresse des deux terres, dCléopâtre), la sœur et épouse du fils de Râ, ḍPtolémée vivant à jamais, aimé de Ptah). La reine, bien que figurée seule officiante dans les tableaux, ne s'affranchit donc pas pleinement de la tutelle de son époux qui, en plus d'être l'acteur principal des scènes adjacentes des montants et du linteau, est systématiquement mentionné dans les inscriptions des deux scènes. Son nom de naissance apparaît dans les textes d'identification de la reine alors que le qualificatif de $n \underline{t r}$.wy mnh.wy, les deux dieux Évergètes, est inscrit à la fin de la série d'épithètes de la reine et à la fin des colonnes marginales royales. Notons enfin que dans les colonnes marginales divines, la reine exhorte les déesses à protéger le roi, alors qu'habituellement c'est l'officiant lui-même qui est soumis à la protection des figures divines. Ainsi, Cléopâtre II est bien figurée seule, mais est toujours étroitement associée à son époux ${ }^{20}$. L'examen des autres épithètes portées par la reine ne permet pas de tirer d'information relative à un statut particulier de cette dernière. Les titres de $h k$ k. . $t$ et $n b . t$ t3.wy sont attestés chez les souveraines ptolémaïques dès le règne d'Arsinoé $\mathrm{II}^{21}$, alors que le groupe sn.t ḥm.t ne présente un réel intérêt, comme nous l'avons mentionné précédemment, que pour les questions de datation du décor. Bien qu'exécutante des rites, la reine ne porte aucun titre ou qualificatif spécifique à une fonction de prêtrise.

[Analyse du décor] Le linteau de la face externe de la porte fonctionne comme un véritable panneau d'affichage de la théologie locale regroupant, dans les scènes centrales, les divinités insulaires principales (Osiris / Isis) et invitées (Khnoum-Râ / Hathor), dans les scènes latérales, deux divinités importantes régnantes liées aux théologies mammisiaque

\footnotetext{
${ }^{20}$ Sur cette question, voir M. MINAS, « Cleopatra II and III: the queens of Ptolemy VI and VIII as guarantor of kingship and rivals of power », communication à paraître faite dans le cadre des journées internationales intitulées Ägypten zwischen innerem Zwist und äußerem Druck. Die Zeit Ptolemaios'VI. bis VIII. (Heidelberg, 17-19 septembre 2007). Qu'il me soit permis de remercier l'auteur qui m’a autorisée à consulter et citer son texte avant publication.

${ }^{21}$ J. QuAegebeur, « Ptolémée II en adoration devant Arsinoé II divinisée », BIFAO 69, 1971, p. 191-217 et p. 204.
} 
(Amon-Râ) et décadaire (Harendotes). Les actions engagées par le souverain (courses et présentation de vin) sont habituelles des linteaux et indépendantes des identités divines.

Les scènes des montants mettent l'accent sur un aspect spécifique de la théologie insulaire, le mythe de la Lointaine. Dans la scène supérieure ouest (fig. $3^{\mathrm{n}^{077}}$, fig. 4), Cléopâtre II fait face à Isis et Nekhbet à qui elle offre un pectoral d'or beb. À l'Est (fig. $3^{\mathrm{n}^{\circ} 78}$, fig. 5), elle agite les sistres devant Nephthys et Ouadjet alors qu'un objet-menat est jeté en travers de son bras droit $^{22}$. Les divinités sont organisées par paire : la figuration de Nephthys répond à celle d’Isis et celle de Ouadjit à celle de Nekhbet. Les séquences d'épithètes des déesses Isis et Nephthys présentent une structure similaire avec d'abord l'attachement fraternel et mythologique des déesses à Osiris ( $h w \quad s n=s$ et $s n . t-n \underline{t} r$ ), puis l'évocation des divinités comme déesses dangereuses (ir.t $R^{\subsetneq}$ ) et enfin leur présentation comme déesses « universelles » $(n b(. t)$ p.t hnww.t ntrr.w). Ces séquences d'épithètes reflètent parfaitement la théologie développée sur l'île de Philae où la déesse Isis, avec ici sa parèdre de toujours, est à la fois protectrice de son frère, actrice des rites décadaires et forme apaisée de la déesse lointaine du fait de son rapprochement avec la déesse Hathor. La présence d'Isis à l'Ouest, c'est-à-dire à gauche, s'explique par la position prédominante de la déesse à Philae. Le choix de lui associer Nephthys à droite, et non Hathor comme cela est souvent observé sur l'île $e^{23}$, indique que les décorateurs ont mis l'accent sur le caractère osirien des déesses, l’évocation de leur aspect de déesse lointaine n’étant faite qu’en seconde position.

A la paire Isis / Nephthys est associé le couple Nekhbet / Ouadjit ${ }^{24}$. Les épithètes des déesses les présentent d'abord comme les représentantes et garantes de la royauté de Haute et Basse

\footnotetext{
${ }^{22}$ L'association aux sistres de l’objet-menat jeté en travers du bras droit de la reine rappelle les représentations des prêtresses d'Hathor à l'Ancien Empire, prêtresses qui étaient reconnaissables à ces objets caractéristiques (E. STAEHELIN, « Menit », LÄ IV, 1982, col. 52 et et A.M. BlACKMAN, The rock tombs of Meir II. The tombchapel of Senbi's son Ukh-Hotep, ASE 23, 1915, pl. 15). La présence de cet objet, étroitement associé à la déesse Hathor, tient certainement plus au contexte dans lequel les représentations de la souveraine apparaissent (action devant des formes de la Lointaine) que d'une identification de la reine à une prêtresse d'Hathor.

${ }^{23}$ Les décorateurs associent souvent Isis (placée à gauche), actrice des rites décadaires, à Hathor, personnification apaisée de la Lointaine. On trouve également la mise en correspondance de deux formes d’Isis, l'une actrice des rites décadaires, l'autre mère divine dans le mammisi. Voir Ad. GuTBuB, « Remarques sur quelques règles observées dans l'architecture, la décoration et les inscriptions des temples de basse époque », dans Fl. Thill, Fr. Geus (éd), Mélanges offerts à J. Vercoutter, Paris, 1985, p. 135-136 et L. AïT AMROUCHEMARTZOLFF, Recherches sur la décoration des pylônes des périodes ptolémaïque et romaine, Thèse inédite soutenue à l’Université Marc Bloch de Strasbourg en 2005, p. 565.

${ }^{24}$ On ne peut s'empêcher de penser à un des pectoraux de Toutânkhamon qui montre le roi protégé par la déesse vautour Nekhbet, également nommée Isis, et la déesse uraeus Ouadjit présentée comme Nephthys. À la grille iconographique première montrant le roi de Haute et Basse Égypte protégée par les déesses tutélaires des deux pays, se superpose une grille osirienne définie par l'aspect du roi et les dénominations des deux déesses. Cet exemple a été présenté et développé par Cl. TRAUNECKER dans Temples, cultes et théologies tardives dans les régions coptite et thébaine. Mémoire d'habilitation inédit présenté en 1992 à l'Université de Lille III, p. 8-10). Je remercie l'auteur de m’avoir donné accès à ce travail inédit.
} 
Égypte. Même si aucune des deux figures n’est porteuse de l'appellation caractéristique d'œil de Râ, différents indices vont pourtant dans le sens de la figuration de formes apaisées de la déesse lointaine. Ainsi, les épithètes de Ouadjit s’achèvent par la séquence «maîtresse du Per-our, dame du Per-neser », séquence qui qualifie Sekhmet dans le rituel d'apaisement de la déesse ${ }^{25}$, alors que les paroles prononcées par Nekhbet la désignent comme celle qui orne le front des souverains, c’est-à-dire la déesse apaisée qui prend la forme de l'uraeus protecteur.

Ce sont donc plusieurs grilles de lecture identitaires qui se superposent pour ces seuls tableaux : une grille relevant du mythe de la Lointaine et une grille osirienne. La figuration de la reine devant ces identités divines doit mériter toute notre attention. L’association de Cléopâtre II, par le biais de l'offrande, aux garantes de la royauté Ouadjit et Nekhbet, démontre bien que la souveraine est considérée comme l'égale du roi. On sait d'ailleurs qu’à compter du règne de Ptolémée VI Philométor, plus précisément dès 163 av. J.-C., l'appellation de pharaons au pluriel ( $\left.p r-{ }^{-} 3 . w\right)$ est employée pour désigner le roi et la reine. Ces mentions apparaissent d'abord dans les textes démotiques puis passent dans la documentation hiéroglyphique des temples dès le début du règne de Ptolémée VIII Evergète $\mathrm{II}^{26}$.

Les actions effectuées par la reine, agitation des sistres et présentation du pectoral beb s’accordent bien avec les caractéristiques des déesses présentées comme des déesses dangereuses. Comme nous l'avons mentionné plus haut, l'agitation des sistres est l'action par excellence qui est effectuée pour apaiser la lionne à son retour de Nubie, alors que l'offrande du pectoral beb est idéale pour calmer la furie de la divinité qui en pare sa poitrine ${ }^{27}$. Les offrandes pratiquées dans les autres tableaux des montants, offrandes qui sont toutes adressées à des divinités féminines, ont le même but : apaiser la Lointaine. Sur les montants,

\footnotetext{
${ }^{25}$ J.-Cl. GoYon, Le rituel du shtp Shmt au changement de cycle annuel, BdE 141, 2006, p. 86.

${ }^{26}$ P.W. Pestman, Chronologie égyptienne d'après les textes démotiques, P.L.Bat. 15, 1967, p. 50. Au temple de Tôd, dans une scène qui peut également être datée du début du règne commun de Ptolémée VIII Evergète II avec Cléopâtre II, les souverains sont désignés comme les « deux Horus » ou les «deux souverains ». C. THIERS, Tôd. Les inscriptions du temple ptolémaïque et romain II. Textes et scènes $n^{o s}$ 173-329, FIFAO 18-2, 2003, $n^{\circ} 285^{1}, 299^{6}$ et $296^{8}$. La scène est commentée dans J.-Cl. GrENIER, « Ptolémée Évergète II et Cléopâtre II d'après les textes du temple de Tôd », dans N. Bonacasa, A. Di Vita (éd.), Alessandria e il mondo ellenisticoromano. Studi in onore di Achille Adriani I, Studi e Materiali 4, Palerme, 1983, p. 33. Une critique quant à la réelle portée historique de la représentation est faite par Fr. CoLIN dans « L'Isis "dynastique" et la Mère des dieux phrygienne. Essai d'analyse d'un processus d'interaction culturelle », ZPE 102, 1994, p. $274^{\text {note }} 17$. Il est intéressant de noter que ces mentions dans le temple de Tôd et les scènes de Philae peuvent toutes être datées du début du règne (pour le titre de sn.t ḥm.t portée par Cléopâtre II à Tôd, voir C. THIERS, Tôd. Les inscriptions du temple ptolémaïque et romain II. Textes et scènes $n^{o s}$ 173-329, FIFAO 18-2, 2003, nº300 ${ }^{3}$ ).

${ }^{27}$ M.-Cl. MiALON, « L'offrande du bijou liturgique beb dans les grands sanctuaires ptolémaïques et romains », Kyphi 1, 1998, p. 68.
} 
et à l’inverse de ce qui est observé sur le linteau, séquences d'actions et d’identités sont donc étroitement liées.

\section{Les scènes provenant du temple de Tôd (annexe II, fig. 6-7)}

Au temple de Tôd, le linteau de la face extérieure de la porte menant à la salle des déesses, désignée par les textes comme une hout-noub ${ }^{28}$, porte deux représentations montrant une souveraine, secondée dans chaque tableau par un officiant masculin et un officiant féminin, qui présente à deux divinités féminines des linges et un onguent (probablement de la myrrhe $^{29}$ ) contenu dans un récipient prenant la forme d'un sphinx ${ }^{30}$. Dans le tableau droit, le personnel associé présente, en accord avec l’offrande de la souveraine, des pots contenant le même produit. En revanche du côté gauche, ils portent sur des plateaux des signes verticaux qui évoquent la fibre croisée et donc le tissu $\left({ }^{\natural}\right)$, mais qui ne sont pas non plus sans rappeler le signe hiéroglyphique $s 3($ ) synonyme de protection.

[Datation] Les textes des deux scènes n’ont pas été inscrits, à l'exception des épithètes précédant les cartouches laissés vides de la reine. Elles la désignent comme la

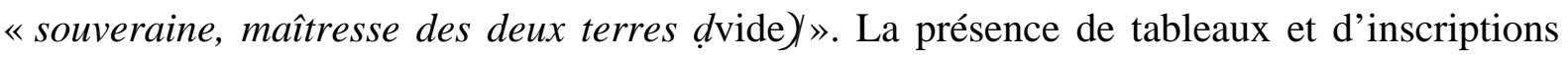
gravés au nom de Ptolémée XII Néos Dionysos dans la salle adjacente des offrandes permet de proposer une identification de la souveraine à Cléopâtre VII sans pour autant que les indices soient déterminants ${ }^{31}$. Il est toutefois plus difficile de préciser à quelle période de son règne ces scènes doivent être rattachées. Les souverains des parois internes de la salle des déesses sont tous anonymes : il pourrait aussi bien s’agir de Ptolémée XII Néos Dionysos, Ptolémée XIII, Ptolémée XIV voire même Ptolémée XV Césarion. Selon les cas, la reine serait figurée en qualité de corégente (règne de Ptolémée XII Néos Dionysos), reine associée à un de ses frères (Ptolémée XIII ou Ptolémée XIV) ou à son fils (Ptolémée XV Césarion).

\footnotetext{
${ }^{28}$ C. THIERS, Tôd. Les inscriptions du temple ptolémaïque et romain II. Textes et scènes $n^{\text {os }} 173-329$, FIFAO 18$2,2003, n^{\circ} 283^{\mathrm{B}}$. La question de la réalité de la hout-noub sera examinée à la fin du paragraphe consacré aux représentations du temple de Tôd.

${ }^{29}$ Dans la salle des déesses, une offrande similaire est présentée devant Sekhmet et le texte précise qu'il s'agit de myrrhe. Un autre tableau montre le roi qui tend à Neith un pot comparable à celui porté par les suivants de la reine et qui contient également de la myrrhe (C. THIERS, op. cit., n²79 et 282).

${ }^{30}$ C. THIERS, op. cit., n²46-247.

${ }^{31}$ Les cartouches de ce souverain apparaissent sur la face extérieure de la porte principale axiale menant à la salle des offrandes et sur les parois nord et sud de cette même salle (C. THIERS, op. cit., nº173-176 et n²35, 242-243).
} 
Cinq colonnes de textes sont inscrites sur les montants de porte. Cléopâtre VII, pour peu que notre identification de la reine soit exacte, est la seule figure royale inscrite en façade de la porte. On ne trouve dans l'ensemble des textes gravés aucune mention d'un souverain mâle. Nous savons que la porte axiale menant à la salle des offrandes a été décorée sous le règne de Ptolémée XII Néos Dionysos, mais la date de la réalisation du décor de la portion de mur faisant la jonction entre les portes axiale et méridionale n’est pas connue. Il est donc fort possible que, pendant un laps de temps plus ou moins long, c'est-à-dire jusqu'à l'inscription des scènes adjacentes du linteau sur la paroi, la reine soit restée sans figure masculine visuellement associée.

[Analyse du décor] En l'absence d'inscriptions, l'identification des divinités du linteau est impossible même si des solutions peuvent être proposées. La coiffe de la première déesse du couple du tableau gauche, l’utérus de vache, est généralement caractéristique de la déesse Tjenenet qui apparaît sous la même forme au revers de la porte ${ }^{32}$. Parmi les trois déesses coiffées des cornes de vache enserrant le disque solaire, doit se trouver au moins une figuration de la déesse Hathor, à l'image de l'association présente au revers de porte, et certainement une image de la déesse Râttaouy.

Dans les deux scènes du linteau, la souveraine apparaît comme l'élément guidant l'action d'un personnel dont les titre et rang ne sont pas spécifiés. Il faut toutefois remarquer que les personnages masculins et féminins portent tous deux des coiffes longues atteignant les épaules et que le costume de la figure masculine est complété par une queue de taureau. Ce complément vestimentaire est d'importance car il permet de rattacher ces personnages à une catégorie bien précise. En effet, la queue de taureau n’est portée que par le roi et les divinités masculines parmi lesquelles sont comptabilisés les génies ${ }^{33}$. Le personnel accompagnant la reine serait donc de nature divine.

L'examen du décor de la face interne de la porte ainsi que des parois internes de la salle des déesses permet sans nul doute d’apporter des informations essentielles à la bonne compréhension de la figuration de la souveraine en façade. Alors que le linteau de la face interne de la porte est occupé par un disque solaire ailé, chaque montant est divisé en trois

\footnotetext{
${ }^{32}$ C. THIERS, op. cit., n²58 et M.-Th. DERCHAIn-URTEL, Synkretismus in ägyptischer Ikonographie. Die Göttin Tjenenet, GOF IV, 8, 1979, p. 6. Ce même emblème peut orner la tête de Meskhenet mais est caractéristique de la déesse Tjenenet dans le temple de Tôd. Pour une représentation de l'utérus de vache coiffant Osiris, voir Fr. DAUMAS, Les mammisis de Dendara, Le Caire, 1959, pl. 61bis et p. $139^{9[11]}$.

${ }^{33}$ G. JÉQUIER, « La queue de taureau insigne des rois d’Égypte », BIFAO 15, 1915, p. 165. Pour des représentations de génies, voir par exemple Edfou XIII, pl. 546-550 ; Fr. DAUMAS, Les mammisis de Dendara, Le Caire, 1959, pl. 56 et C. THIERS, Y. VolOKHINE, Ermant I. Les cryptes du temple ptolémaïque, MIFAO 124, 2005, p. 56-58
} 
scènes. Les tableaux inférieurs sont occupés par la figuration des quatre déesses hippopotame Meskhenet, déesses protectrices des naissances divines et royales ${ }^{34}$. Dans les tableaux supérieurs, un personnel agit sur les naoi et les statues divines féminines qu'ils contiennent ${ }^{35}$. La présence de longues robes et d'une poitrine nettement marquée permet d'affirmer sans nul doute que ce personnel, qui se caractérise par une coiffe courte, est féminin. Aucune inscription n’accompagne les tableaux. Néanmoins, le texte 254 gravé sur le montant interne sud de la porte mentionne un personnel féminin et masculin chargé d'œuvrer pour la déesse Oupeset. Ce personnel est désigné comme les «pures» ( $w^{r} b . w t$ mon entrent» (cky.w disparaît des scènes sculptées sur les parois latérales mais reparaît dans une scène inscrite dans le tableau de l'embrasure ouest de la porte percée dans le mur sud du temple, ouvrant sur la salle hypostyle. Là, une femme qui entre dans le temple est purifiée par Horus et Thot ${ }^{37}$. Les nom et qualificatif de ce personnage ne sont pas préservés, toute la partie supérieure de la scène étant manquante, mais le bandeau de soubassement précise que cette porte est celle par

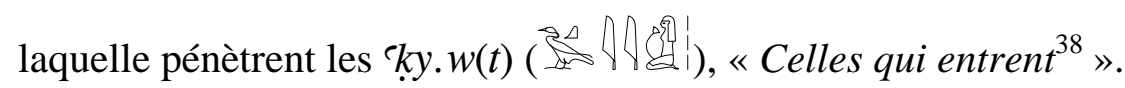

\footnotetext{
${ }^{34}$ C. THIERS, op. cit., n²52-253 ; M.-T. DERCHAIN-URTEL, « Mesechenet », LÄ IV, 1982, col. 107; Em. CHASsinat, Le mystère d'Osiris au mois de Khoïak 1, Le Caire, 1966, p. 339-341 ; D. MEEKs, « Génies, anges, démons en Egypte », dans D. Meeks et alii, Génies, anges et démons, SO 8, 1971, p. 39. La figuration des quatre Meskhenet n’est pas rare, mais la forme anthropomorphe est généralement préférée à la forme animale. Voir par exemple, Em. CHASsinAT, Le mammisi d'Edfou, MMAF 13, 1910, p. $44^{13}$; Dendara II, pl. 127 (p. $148^{13}$ ) ; Dendara X, pl. 99 (p. $206^{8}$ ) et pl. 150 (p. $269^{11}$ ) ; Dendara XI, pl. 78 (p. 108 ${ }^{11}$ ) ; Fr. DAUMAS, Les mammisis de Dendara, Le Caire, 1959, pl. 59bis (p. $\left.113^{17}\right)$; Esna III, $n^{\circ} 311^{13}$.

${ }^{35}$ C. THIERS, op. cit., nº255-258.

${ }^{36}$ C. THIERS, op. cit., p. $152^{2-3}$.

${ }^{37} \mathrm{~Wb} \mathrm{I}, 232^{13}$. Les scènes montrant la purification d'une femme ne sont pas très nombreuses. Un autre exemple est attesté sur un bloc provenant de la chapelle rouge de Karnak et concerne une épouse divine (Fr. BURGOS, Fr. LARCHÉ, La chapelle rouge. Le sanctuaire de barque d'Hatschepsout I. Fac-similés et photographies des scènes, Paris, 2006, p. 216 (bloc n²92) et P. LACAU, H. CHEVRIER, Une chapelle d'Hatshepsout à Karnak I, Le Caire, 1977, p. 330, § 568).

${ }^{38}$ Le terme $k$ y.t est bien attesté dans la littérature et désigne une servante ou la déesse Hathor en qualité de servante du dieu solaire ( $W b$ I, 232 ${ }^{13-14}$ ). Toutefois, dans ce contexte précis et étant donné la localisation de la représentation, dans le passage d’une porte, $` k y . t$ est très certainement la version féminine du terme $₹ k y$ (« celui qui entre »; $W b \mathrm{I}, 232^{12}$ ) qui est une manière de désigner une catégorie de personnel entrant dans le temple (H. DE MEulEnAERE, « Recension de l'ouvrage de W. Otto ( $\dagger$ ), Beiträge zur Hierodulie im hellenistischen Ägypten, (ABAW 29, 1950) », BiOr 8, 1951, p. 222 ; R. EL-SAYED, « Quelques précisions sur l'histoire de la province d'Edfou à la $2^{\mathrm{E}}$ période intermédiaire (étude des stèles JE 38917 et 46988 du Musée du Caire) », BIFAO 79, 1979, p. $184^{\mathrm{b}}$ ). Dans le temple d’Edfou, le terme ` $k y . w$ désigne le personnel sortant du lac sacré qui apporte les offrandes dans le temple (Edfou VII, $18^{3-4}$ ). À plusieurs reprises, ce même terme est employé dans des énumérations de titres de prêtrise (G. DARESSY, « Description des monuments épigraphiques trouvés à Karnak en 1921-1922 », ASAE 22, 1922, p. 266 ; Edfou III, $360^{12}$; Dendara XI, $132^{11}$; J. DE MORGAN, Catalogue des monuments et inscriptions de l'Égypte Antique III. Kom Ombos II, Vienne, 1895, n878). H. de Meulenaere estime donc qu'il faut « considérer le terme ‘ $k j . w$ comme un participe substantivé désignant l'ensemble des personnes, prêtres ou autres, ayant le droit d'entrer dans le temple. Dès lors, une seule traduction s'imposerait : "ceux qui peuvent entrer". » (BiOr, 8, 1951, p. 222). Ce vocable ne doit donc pas être
} 
L’apparence des opérantes sculptées sur la face interne de la porte de la salle des déesses et dans l'embrasure de la porte ouvrant sur la salle hypostyle est très différente de celle des personnages féminins figurés en façade de la salle des déesses, à la suite de la reine. Alors que les compagnes de la souveraine portaient des coiffes longues, les officiantes de la salle des déesses se caractérisent par une perruque courte, à l'image de celle que peuvent porter les prêtres $^{39}$. Leur représentation n’est pas sans rappeler les pleureuses divines associées au lit mortuaire d'Osiris qui peuvent prendre les noms d'Isis, Nephthys, Merkhetes ou Chentayt ${ }^{40}$. Dans le petit temple romain d'el-Qal'a, les deux divinités maternantes associées à la Grande déesse, Tameretentaneb et Tairetepertem, peuvent porter cette coiffe courte ${ }^{41}$. Il faut enfin remarquer qu'une des officiantes porte des sandales, attribut absent de toute autre représentation ${ }^{42}$.

Quant aux parois latérales de la salle, elles sont occupées par vingt-quatre tableaux d’offrande dans lesquels le roi est l'unique officiant devant des divinités exclusivement féminines, ce qui a valu à cette pièce l'appellation de salle des déesses.

[Fonction de la salle des déesses] La raison de la présence de la reine en façade de cette salle semble être motivée à la fois par le sexe des divinités et par la présence de ce personnel féminin dont la fonction exacte reste à définir, en prenant soin de distinguer les personnalités divines sculptées en façade, à la suite de la reine, des opérantes à coiffe courte intervenant sur les naoi. Cela revient inévitablement à s’interroger sur la fonction de cette pièce.

Désignée par les textes comme une hout-noub, c'est-à-dire «un lieu où s'achevaient la préparation et la consécration des statues et accessoires liturgiques avant leur utilisation dans le culte ${ }^{43}$ », la salle ne présente pourtant pas un programme décoratif caractéristique de ce type d'espace ${ }^{44}$, en tous les cas tel que l'on peut se l'imaginer à partir des exemples bien

classé parmi les noms de fonction désignant des catégories sacerdotales ( $h m-n \underline{t} r$, itt- $n \underline{t} r$ par exemple) mais parmi les noms d'action qui précisent une action définie et implique tous les protagonistes susceptibles d'effectuer cette action. Les ‘ $k y . w$ sont les personnes susceptibles d’entrer dans le temple pour y effectuer une tâche précise. Ils ne font donc pas obligatoirement partie du personnel sacerdotal.

${ }^{39}$ Voir par exemple Edfou I, pl. 38 $8^{\mathrm{a}-\mathrm{d}, \mathrm{e}, \mathrm{j}, \mathrm{n,} \mathrm{o}}$ ou Dendara VII, pl. 666, 668-671, 677-678.

${ }^{40}$ Dendara X, pl. 52, 53, 96-97, 104-107, 243, 247 et 257.

${ }^{41}$ L. Pantalacci, Cl. TrauneCKer, Le temple d'el-Qal`a II, Le Caire, 1998, n¹86, 210, 213 et p. 4 , § 7.

${ }^{42}$ C. THIERS, op. cit., $\mathrm{n}^{\circ} 255$.

${ }^{43} \mathrm{Ph}$. Derchain, « L'Atelier des orfèvres à Dendara et les origines de l'Alchimie », CdE 65, n 130, 1990, p. 220.

${ }^{44}$ Ce fait a déjà été relevé par C. Thiers et W. Waitkus. Voir C. THIERS, op. cit., p. XV et C. THIERS, « Ouadjyt et la lac du saule », dans L. Gabolde (éd.), Hommages à Jean-Claude Goyon, BdE 143, 2008, p. 375-376 ; 
connus de Dendéra ou de Karnak ${ }^{45}$. Les parois latérales de la pièce sont occupées par des présentations d'offrande tout à fait habituelles. Il y a bien les tableaux montrant un personnel agissant sur des naoi et des statues, mais aucune représentation évoquant clairement la houtnoub avec, par exemple, une ouverture de la bouche de la statue ou du matériel consacré ${ }^{46}$. Ptah et Khnoum, patrons des artisans présents à Dendéra et à Karnak, sont absents des parois de la salle des déesses.

Nous avons noté que les pleureuses d’Osiris pouvaient être représentées avec des coiffes courtes comparables à celles portées par les femmes agissant sur les statues dans les naoi. Plus qu'un personnel modelant les statues, ces femmes pourraient plutôt appartenir à un personnel de soin, d'entretien. Il faut d'ailleurs préciser que les textes des hout-noub ne font jamais référence à un personnel artisan féminin même lorsqu’il est question de la confection de statues féminines ${ }^{47}$. La ligne de texte inscrite sous la scène de purification de l’officiante précise que les $k y . w(t)$ entrent afin d’accomplir les cérémonies (ir ỉrw) pour Tjenenet et Hathor, conformément à ce qui existe dans l'Iounou du Sud ${ }^{48}$. Dans l'inscription 254 gravée sur la face interne de la porte, les officiantes ont la même fonction ${ }^{49}$. La séquence ỉr ỉrw peut être comprise de deux manières, selon le sens retenu pour ỉrw. Ce terme peut désigner l'image, l'aspect de la divinitét ${ }^{50}$. Dans ce cas, ces officiantes seraient les réalisatrices des images divines. Toutefois, nous avons vu qu’aucun personnel féminin n’était attesté dans les

W. WAITKUS, « Recension de l’ouvrage de C. Thiers, Tôd. Les inscriptions du temple ptolémaïque et romain II. Textes et scènes nos 173-329, FIFAO 18-2, 2003 », Orientalia 74, 2005, p. 423-424.

${ }^{45}$ Pour la hout-noub du temple de Dendéra, voir Dendara VIII, pl. 802-814 et p. 127-145 ainsi que Ph. Derchain, «L'Atelier des orfèvres à Dendara et les origines de l'Alchimie », CdE 65, n 130, 1990, p. 219241. Pour l'exemple de Karnak, voir Cl. TrAunECKER, «Le "Château de l'Or" de Thoutmosis III et les magasins nord du temple d'Amon », CRIPEL 11, 1989, p. 89-111. Cl. Traunecker nous signale également que la chambre XV de la tombe de Padiaménopé à Thèbes (TT 33) est désignée par les textes comme une hout-noub. Les parois présentent une représentation de Ptah, la barque de Sokaris et plusieurs figurations d’Osiris Hemag (J. DüMICHEN, Der Grabpalast des Patuamenap in der thebanischen Nekropolis 1, Leipzig, 1884, pl. 1 et F. VON BISSING, « Das Grab des Petamenophis in Theben », ZÄS 74, 1938, pl. IIb).

${ }^{46}$ Dendara VIII, pl. 811et p. $143^{10-16}$; Cl. TRAUNECKER, « Le "Château de l'Or" de Thoutmosis III et les magasins nord du temple d'Amon », CRIPEL 11, 1989, p. 96.

${ }^{47} \mathrm{Ph}$. Derchain, « L'Atelier des orfèvres à Dendara et les origines de l'Alchimie », CdE 65, n 130, 1990, p. 233-324. Sur le personnel des hout-noub, voir A. VON LIEVEN, « Im Schatten des Goldhauses.

Berufsgeheimnis und Handwerkerinitiation im Alten Ägypten », SAK 36, 2007, p. 147-155. Dans les textes inscrits dans le passage de la porte menant à la salle des déesses, il n’est pas question de ce personnel féminin; on ne parle que des prêtres (`k3.w) qui sont les seuls susceptibles de voir la divinité. Voir C. THIERS, op. cit., p. $140^{6-7}$.

${ }^{48}$ Ét. Drioton, G. Posener, J. VANDIER, J.-Cl. Grenier, Tôd. Les inscriptions du temple ptolémaïque et

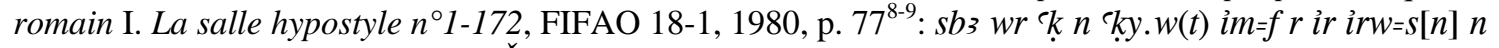
T3tnnt Hw.t-Hr mi.tt hpr m 'Iwnw-Šme.

${ }^{49}$ C. THIERS, op. cit., p. $152^{2-3}$.

${ }^{50} \mathrm{~Wb} \mathrm{I}, 113^{14}$. 
hout-noub pour réaliser les statues. De plus, dans les textes de Dendéra décrivant la confection des images divines, ỉrw n’est jamais employé pour qualifier les effigies divines,

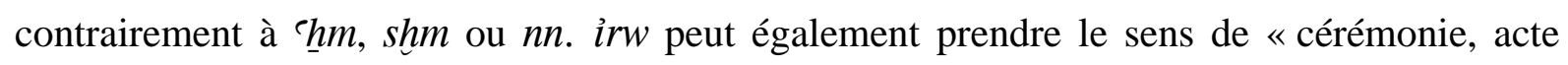
liturgique » ce qui convient bien à ce contexte, d'autant plus que la séquence ìr ỉrw, « accomplir une cérémonie », est bien attestée ${ }^{51}$. Ces femmes n’interviennent donc pas dans la réalisation des statues divines, mais appartiennent à un personnel féminin chargé d’accomplir des cérémonies en liaison avec Tjenenet et Hathor.

Ces officiantes doivent être distinguées de celles associées à la reine et qui s’apparentent, semble-t-il, à un personnel divin. L'offrande de linges et myrrhe en façade n'est pas caractéristique des hout-noub. Néanmoins, il n’est pas rare que ces produits soient présentés dans un contexte de naissance, à la divinité parturiente. C'est le cas sur les parois de la chambre sud célébrant la naissance de l'enfant Horus dans le temple d'Opet ${ }^{52}$. Ce contexte de naissance semble être confirmé par la figuration, au revers de la porte, des quatre Meskhenet et s'accorde parfaitement avec la personnalité de Tjenenet qui intervient dans les naissances ${ }^{53}$.

La salle des déesses, bien que désignée par les textes comme une hout-noub, s’apparente plus à un espace dans lequel étaient pratiquées des cérémonies sur les effigies des déesses Hathor et Tjenenet, cérémonies qui étaient à mettre en rapport avec la personnalité de Tjenenet et en particulier son rôle de protectrice des naissances. Ces cérémonies nécessitaient l'intervention d'un personnel de soin féminin qui est représenté entrant dans le temple et agissant sur les naoi. Ce contexte très féminin a justifié la représentation, en façade de la salle, de la souveraine en qualité d’officiante accompagnée de génies masculins et féminins. Ces protagonistes s’intègrent à la thématique développée en présentant aux divinités des linges, de la myrrhe et des symboles de protection.

\section{Les quatre représentations du mammisi d'Erment}

En l'absence d'informations suffisantes pour un commentaire plus complet, les scènes du mammisi d’Erment ne seront qu'évoquées et non intégralement étudiées. Ol. Perdu a

\footnotetext{
${ }^{51} \mathrm{~Wb}$ I, $113^{11}$.

${ }^{52}$ C. DE WIT, Les inscriptions du temple d'Opet à Karnak II. Index, croquis, position des planches, BiAe 12, 1962, pl. 5-6.

${ }^{53}$ M.-Th. Derchain-URTEL, Synkretismus in ägyptischer Ikonographie. Die Göttin Tjenenet, GOF IV, 8, 1979, p. 34-36.
} 
relevé un grand nombre de tableaux figurant une reine officiant seule. Seules deux de ces représentations semblent avoir en miroir des scènes où la souveraine agit. Elles occupent le second registre des parois ouest et est du sanctuaire (deux scènes par registre).

Les seules informations dont nous disposons pour reconstituer la décoration de ce registre sont fournies par K.R. Lepsius et se limitent à une description très rapide des tableaux précisant (parfois) la nature de l’offrande présentée et le nom des divinités bénéficiaires (à défaut de produire un nom, l’auteur décrit les attributs des divinités).

Sur la paroi ouest, la reine présente les couronnes de Haute et Basse Égypte à trois déesses : la première porte cette même couronne, les deux suivantes sont léontocéphales. La scène adjacente voit l'offrande d'un bandeau de cheveux à trois divinités féminines dont deux sont porteuses de la couronne rouge ${ }^{54}$. Des scènes de la paroi correspondante, nous n'avons que peu d’informations. Les offrandes ne sont pas précisées; K.R. Lepsius identifie les trois divinités de la première scène à trois formes de Râttaouy et mentionne Nekhbet, Ouadjit et une troisième divinité, en qui il faut reconnaître Iousâas, pour la seconde représentation ${ }^{55}$.

\section{B. Commentaire}

Ces cas de figure mettant en scène des souveraines officiant dans deux scènes se répondant sont suffisamment rares pour que les caractéristiques de ces représentations et les contextes dans lesquels ces scènes apparaissent soient comparés. Compte tenu du nombre relativement limité d'attestations, ce commentaire, axé sur un ensemble de points dont l'étude nous a paru pertinente, sera susceptible d'évoluer, d’être précisé ou modifié en fonction des nouvelles attestations qui pourraient apparaître dans la documentation.

\section{Localisation des représentations}

Les attestations présentant des scènes doubles de reines officiant seules sont toutes localisées en Haute Égypte (Philae, Elkab et Tôd). En fait, ce phénomène n’est pas limité à ces cas de figure mais concerne toutes les scènes figurant la souveraine en qualité de seule

\footnotetext{
${ }^{54}$ PM V, p. $155^{25-26}$ et LD Text IV, p. 10.

${ }^{55}$ PM V, p. 156 $6^{29-30}$ et LD Text IV, p. 11. Pour l'identification de Iousâas, voir J. VANDIER, « Iousaâs et (Hathor) Nebet-Hétépet- I », RdE 16, 1964, p. $140^{\mathrm{XCVI}}$.
} 
officiante, qu'elle soit ou non mise en correspondance avec sa propre image ${ }^{56}$. Ce fait tient certainement plus à la mauvaise ou partielle conservation des monuments de Basse et Moyenne Égypte qu’à une réelle volonté d’exclure du décor des parois les représentations de la souveraine.

Les tableaux présentant une reine comme seule officiante ne sont pas caractéristiques d'un type d'édifice précis ni même d'une partie spécifique de ce dernier ${ }^{57}$. Les représentations peuvent être localisées dans un espace d'accès relativement restreint et donc être difficilement visibles ou, à l'inverse, être très exposées comme sur la face externe d'un mur d'enceinte du temple d'Edfou ${ }^{58}$.

Concernant les trois exemples retenus où la figuration de la reine est doublée, une tendance peut être relevée. Ces scènes apparaissent toujours sur ou à proximité de portes : à Tôd, ce sont deux scènes de linteau, à Philae, deux scènes supérieures de montants et à Elkab les deux tableaux encadrent la porte. Ce fait relève-t-il de la coöncidence ou d'une réelle volonté d'associer à ces espaces les figurations doubles ? Aucun indice ne permet de trancher en faveur de l'une ou l'autre des hypothèses. En tous les cas, la localisation de ces scènes au niveau des portes permet sans nul doute de plus encore les mettre en valeur.

Si les tableaux sont tous à mettre en relation avec des portes, on observe dans chaque cas des contextes extrêmement différents, car les portes concernées ne commandent pas l'accès à des espaces de même nature. Dans l'exemple de Philae, la porte ouvre sur la partie arrière du temple, au spéos d’Elkab sur le sanctuaire et dans le cas de Tôd sur une salle spécifique du temple. À Philae, lorsque Ptolémée VIII Evergète II prend le pouvoir, le projet de monumentalisation du site engagé par Ptolémée VI Philométor est déjà arrivé dans une seconde phase puisque les constructions sont achevées et les phases de décoration entamées ${ }^{59}$. Ptolémée VIII Evergète II poursuivra ce projet en ordonnant l’agrandissement du mammisi et

\footnotetext{
${ }^{56}$ Voir le catalogue des représentations présenté par Ol. PERDU dans « Souvenir d’une reine ptolémaïque officiant seule », ZÄS 127, 2000, p. 146-149. Cela concerne les sites de Philae, Edfou, Kom Ombo, Coptos et Erment.

${ }^{57}$ Ils apparaissent aussi bien dans le corps des temples (parois, colonnes) que sur les murs extérieurs ou dans des chapelles.

${ }^{58}$ Edfou XIV, pl. 642. La scène présente Cléopâtre Bérénice III offrant du vin et du lait à Hathor et Harsomtous. La scène en miroir dans la série liturgique correspondante voit Ptolémée X Alexandre I officier.

${ }^{59}$ Sur cette question, voir G. HAENY, « A short architectural history of Philae », BIFAO 85, 1985, p. 197-234 et M. MiNAS, « Die Dekorationstätigkeit von Ptolemaios VI. Philometor und Ptolemaios VIII. Euergetes II. an ägyptischen Tempeln (Teil 2) », OLP 28, 1997, p. 102-108. Le nom de Ptolémée VI Philométor est présent dans les scènes de la porte percée dans le mole ouest du premier pylône menant au mammisi (face externe et passage, $\mathrm{PM} \mathrm{VI}^{2}$, p. $212^{93-102}$ ), ainsi que dans les textes et représentations associées aux portes ouvrant sur le mole est et donnant accès aux chambres internes du rez-de-chaussée et à la volée d'escalier (PM VI², p. $212^{114-116}$ et p. $212^{105-106}$ ).
} 
la réalisation de la décoration du portique précédant les chambres annexes du temple dans la section est de la cour. La mention de Cléopâtre III dans les textes recouvrant ces espaces indique que ces phases de décoration sont postérieures à celle qui a vu la sculpture des figures de la porte et qui constitue donc le premier projet mis en chantier après l'arrivée de Ptolémée VIII Evergète II au pouvoir. Il faut donc s’imaginer, au début de ce règne, un personnel évoluant dans la cour du temple qui ne présente alors pour seuls éléments décorés environnants que les tableaux des portes. Les figures de Cléopâtre II étaient particulièrement mises en valeur, au sommet des montants, et en façade du temple.

À Elkab, la disposition devait être tout aussi remarquable. Certes, les scènes de la porte voyaient le roi officier, mais les scènes les plus visibles étaient sans nul doute ces grands tableaux encadrant la porte, quand bien même surmontaient-ils d'autres représentations figurant éventuellement le souverain comme officiant ${ }^{60}$. Enfin, à Tôd, seule la reine officie sur la porte, les autres espaces décorés étant occupés par des textes. Dans les trois cas, les scènes sont donc mises en valeur ce qui ne pouvait être que volontaire.

\section{Le statut des souveraines et la manière de les nommer}

Dans les trois cas rencontrés, les souveraines sont différentes : Cléopâtre II à Philae, Cléopâtre III à Elkab et probablement Cléopâtre VII à Tôd. Comme nous l'avons vu, la décoration de la porte de Philae date des premières années du règne de Ptolémée VIII Evergète II. Cléopâtre II apparaît dans les scènes en sa qualité de reine associée au règne du souverain : elle est la sœur et épouse de Ptolémée VIII Evergète II et, au moment où la scène est inscrite, n'a jamais exercé seule le pouvoir ${ }^{61}$. La souveraine figurée dans les tableaux d’Elkab présente un statut différent : Cléopâtre III est la reine mère qui a hérité du pouvoir par testament et qui est associée à son fils Ptolémée IX Sôter I $^{62}$. Elle détient donc

\footnotetext{
${ }^{60}$ Le relevé de Nestor L’Hôte ne laisse pas deviner la présence de scènes sous les représentations de la reine, mais sur photographies, on distingue nettement, sous le tableau est, les traces d'une scène inférieure (Ph. Derchain, Elkab I. Les monuments religieux à l'entrée de l'Ouady Hellal, Bruxelles, 1971, pl. 8 et 14).

${ }^{61}$ Cléopâtre II a bien connu une période pendant laquelle elle a exercé seule le pouvoir, entre 132/131 et 130 avant J.-C., c'est-à-dire après la sculpture des scènes de la porte du second pylône. Voir G. HöLBL, Geschichte der Ptolemäerreiches: Politik, Ideologie und religiöse Kultur von Alexander dem Großen bis zur römischen Eroberung, Darmstadt, 1994, p. 174-179.

${ }^{62}$ JUSTIN, Epitoma historiarum philippicarum, XXXIX, $3^{1-2}$. « Tandis que le royaume de Syrie était le théâtre de ces discordes et de ces parricides, le roi d’Égypte, Ptolémée mourut, laissant sa couronne à sa femme et à celui de ses deux fils qu'elle choisirait, comme si vraiment l'Égypte devait être plus tranquille que le royaume de Syrie, quand la mère, ayant choisi un de ses fils, aurait l'autre pour ennemi. » (Traduction Ém. Chambry et
} 
indéniablement une forte influence dans les affaires du pays. Enfin, Cléopâtre VII, selon la datation des reliefs, est figurée soit en qualité de corégente, soit en qualité de reine associée à un de ses frères ou à son fils. En tous les cas, elle exerce réellement le pouvoir. Même s’il est indéniable que Cléopâtre III et Cléopâtre VII sont deux souveraines qui ont eu une forte influence politique, la figuration de Cléopâtre II est là pour prouver que la présence de ces scènes ne peut s'expliquer uniquement par le fait que ces reines ont un jour concentré entre leurs mains le pouvoir.

À ces différences de statut s'ajoutent des variantes dans la manière de nommer la reine. À Philae, Cléopâtre II est figurée seule dans deux scènes pour mettre en avant une opposition féminin / masculin. Comme nous l’avons mentionné, sa titulature se compose d'épithètes comprenant deux cartouches : le premier la concerne directement et la prénomme Cléopâtre, le second est intégré à l'ensemble des épithètes qui qualifie la reine et précise sa relation avec le souverain régnant (sœur et épouse). Dans ces deux scènes, l’isolement de la souveraine n'est qu'iconographique, les textes se chargeant de rattacher étroitement la reine au roi régnant.

De ce point de vue, la situation observée dans les scènes d'Elkab et de Tôd est fort différente. À Tôd, les textes de la scène n’ont pas été gravés dans leur intégralité, mais la titulature de la reine ne comprenait qu'un seul cartouche. À Elkab, les textes sont mal conservés, mais là encore, seul un cartouche est sculpté au nom de la reine alors que le roi, son fils, n’est pas mentionné dans les colonnes marginales, ni même évoqué par l'emploi de l'épithète désignant le « couple » régnant Ptolémée IX Sôter II / Cléopâtre III, Theoi Philometores Soteres ${ }^{63}$. Dans ces deux cas, il est question d'une séparation totale des deux éléments régnant, l'association du roi ne pouvant se faire que par l'observation des scènes et éléments de décoration adjacents. Dans le cas d'Elkab, peut-être est-ce également valable pour Tôd, cette présentation traduit une réalité politique : Cléopâtre III règne en association avec un fils et non un époux. Toutefois, les situations observées au spéos d’Elkab et dans le temple de Philae ne peuvent servir à établir une règle dictant le nombre de cartouches inscrits en fonction de la position de la souveraine au sein du pouvoir royal. En effet, dans les représentations montrant Cléopâtre III officiant seule dans le temple d’Edfou, représentations

\footnotetext{
L. Thély-Chambry, Paris, 1936). La question du testament de Ptolémée VIII Evergète II a été réexaminée par L. Criscuolo dans le cadre des journées internationales intitulées Ägypten zwischen innerem Zwist und äußerem Druck. Die Zeit Ptolemaios’VI. bis VIII. à Heidelberg (« I testamenti di Tolemeo VIII », communication à paraître).

${ }^{63}$ G. HöLBL, Geschichte der Ptolemäerreiches: Politik, Ideologie und religiöse Kultur von Alexander dem Großen bis zur römischen Eroberung, Darmstadt, 1994, p. 184.
} 
qui sont également datées de son règne commun avec Ptolémée IX Sôter II, la souveraine est parfois accompagnée d'un seul cartouche suivant directement une énumération de titres ${ }^{64}$. Dans d'autres cas, ses épithètes sont plus développées et la désignent comme la mère du souverain régnant faisant alors apparaître un second cartouche au nom de Ptolémée ${ }^{65}$.

\section{Les caractéristiques vestimentaires des souveraines}

À première vue, les images des reines présentes à Philae, Elkab et Tôd sont très semblables. Les souveraines portent toutes une robe moulante et dans une scène au moins d’Elkab et une de Tôd, Cléopâtre a le cou orné d’un large collier. Les autres représentations sont trop endommagées pour juger de la présence ou non du bijou. Ce dernier constitue une parure habituelle de la reine, parure qui peut être complétée par des bracelets de bras ${ }^{66}$. Dans les six scènes concernées, la reine est coiffée d’une perruque agrémentée d’un bandeau noué à l'arrière et d'un uraeus dressé sur le front. Sur cette perruque repose la coiffe hathorique alliant des cornes de vache enserrant un disque solaire à deux hautes plumes ${ }^{67}$. Il s’agit de la coiffe portée habituellement par les souveraines ptolémaïques ${ }^{68}$. À Tôd, la coiffe

\footnotetext{
${ }^{64}$ Edfou III, pl. 83 et p. $354^{21-23}$.

${ }^{65}$ Voir par exemple Edfou X, pl. 107 (texte en Edfou IV, $372^{6}-372^{16}$ ) et Edfou X, pl. 146 (texte en Edfou VI, $82^{1}-84^{8}$ ). Cette dernière scène doit être considérée avec prudence. La reine est figurée, accompagnée des filles et femmes de Bousiris, Pe et Dep, en train d'accueillir Horus victorieux. Cléopâtre III est ici identifiée à la déesse Isis et il est normal que sa qualité de mère du souverain placé sur le trône soit mise en avant par l'association du cartouche de son fils au sien.
}

${ }^{66}$ Voir les nombreux exemples proposés par M. MinAs dans « Macht und Ohnmacht. Die Repräsentation ptolemäischer Königinnen in ägyptischen Tempel », APF 51, 2005, p. 127-154.

${ }^{67}$ Sur cette coiffe, voir M. MALAISE, « Histoire et signification de la coiffure hathorique à plumes », SAK 4, 1976, p. 215-236.

${ }^{68}$ J. QUAEGEBEUR, « Reines ptolémaïques et traditions égyptiennes », dans H. Maehler, V.M. Strocka (éd.), Das ptolemäische Ägypten. Akten des internationalen Symposions 27.-29. September 1976 in Berlin, Mayence, 1978, p. 257. La perruque simple est, en de rares occasions, remplacée par la dépouille de vautour, formant ainsi une composition caractéristique des têtes des déesses et non plus des reines. Cette association est bien connue au Nouvel Empire et attestée sur les têtes des souveraines (voir par exemple LD III, pl. 147, 172, 174, 175). À la période lagide, cette coiffe se trouve, à de rares exceptions, exclusivement sur le chef des déesses, en particulier Hathor. Voir H. JunKeR, E. WINTER, Das Geburtshaus des Tempels der Isis in Philä, DÖAW Sonderband, 1965, p. 70, 86, 122, 138, 154, 161, 162, 180, 200, 220 ou 286 ; P. Du BouRguet, Le temple de Deir al-Médîna, Textes édités et indexés par L. Gabolde, MIFAO 121, 2002, n¹4, 18 ou encore G. ROEDER, Les temples immergés de la Nubie-Der Tempel von Dakke II, Le Caire, 1930, pl. 42, 101. Des divinités rapprochées ou identifiées à Hathor peuvent également porter cette coiffe comme Henouttaouy ou Maât à Deir el Médineh (P. Du BourGUET, op. cit., nº 2, 7, 27, 72, 83, 106, 120, 189 pour Maât et nº174 pour Henouttaouy).

Cette association dépouille de vautour / coiffe hathorique apparaît également sur la tête des reines, mais en un nombre d'occasions très réduit. Sur les 42 attestations de souveraine officiant seule qui ont été recensées, la reine n'est coiffée de cette composition que dans deux cas. Cela concerne une représentation de Bérénice II ( ?) dans le mammisi de Philae, une autre de Cléopâtre VII dans le temple de Kom Ombo (H. JunKER, E. WinTER, 
hathorique repose directement sur la perruque. À Philae et à Elkab, la jonction est opérée par un mortier qui est habillé, dans la représentation est d’Elkab, d’uraei. L’association de ce support avec la couronne hathorique n'est pas nouvelle et bien attestée au Nouvel Empire ${ }^{69}$. Bien que moins fréquente à la période ptolémaïque, elle n’est pas spécifique à la figure de Cléopâtre III puisqu’on la trouve déjà sur la tête de Bérénice II dans les tableaux de la porte d'Evergète à Karnak ou du propylône de Montou à Karnak-Nord ${ }^{70}$. L'association semble être toutefois relativement rare sur la tête des souveraines ptolémaïques.

\section{Le caractère féminin des contextes dans lequel apparaissent ces}

\section{représentations}

En étudiant le cas d’Elkab, Ol. Perdu avançait l’idée que la présence de deux déesses féminines pouvait suffire à justifier la double figuration de la reine. Il écrit ainsi « Dès lors, on peut se demander si la présence régulière de la reine devant Nekhbet ne résulte pas de cette tendance à vouloir associer à une divinité un officiant du même sexe pour accentuer la coloration "masculine" ou "féminine" de la composition. » ${ }^{71}$. La présence de la souveraine se justifierait donc par le sexe de la divinité bénéficiaire des offrandes.

À Philae, la reine apparaît en façade de la porte, parmi les scènes des montants qui figurent des identités divines exclusivement féminines. Comme à Elkab, on pourrait admettre que ce contexte féminin justifie la figuration d'un officiant féminin. Toutefois, les choses s’avèrent plus complexes. L’ensemble de la décoration de la porte du second pylône de Philae est axé sur le mythe de la Lointaine et les divinités féminines figurées en façade ne sont que

op. cit., p. 132 et J. DE MorgAn, Catalogue des monuments et inscriptions de l'Égypte Antique II. Kom Ombos I, n³47-348 et idem. Kom Ombos II, n915). Dans l’ensemble des représentations de temples, ce sont plusieurs reines qui peuvent porter cette coiffe: Arsinoé III (Edfou I, pl. 19), Cléopâtre II (Edfou II, pl. 42a et J. DE MorgAn, op. cit., n526-528) et Cléopâtre III (Edfou III, pl. 75).

${ }^{69}$ M. MALAISE, « Histoire et signification de la coiffure hathorique à plumes », SAK 4, 1976, p. 216 et pour un exemple de représentation, voir Medinet Habu V, pl. $310^{\mathrm{E}}$. La coiffe est ici associée à la dépouille de vautour. Il est également fréquent que les souveraines coiffée de la couronne agrémentée du kalathos d'uraei portent au front le double uraeus (voir par exemple le cas de Tiyi, épouse d'Amenhotep III dans The tomb of Kheruef, Theban Tomb 192, by the Epigraphic Survey, in cooperation with the Department of Antiquities in Egypt, OIP 102, 1980, pl. 26).

${ }^{70}$ P. CLÈRE, La porte d'Evergète à Karnak II, MIFAO 84, 1961, pl. 13, 16, 31, 32 ou encore 43 ; S.H. AUFRÈRE, Le propylône d'Amon-Rê-Montou à Karnak-Nord, MIFAO 117, 2000, n75-76. Dans les scènes de la porte d’Evergète, le kalathos d'uraei est également présent sur la tête des déesses (Râttaouy, Hathor, Nehemetâouay, Ipet, Isis et Nephthys) et fait le lien entre la dépouille de vautour et la couronne portée (voir pl. 7-8, 12-13, 16, 22-24, 28-33, 42, 45, 62-63 et 68).

${ }^{71}$ Ol. PERDU, « Souvenir d'une reine ptolémaïque officiant seule », ZÄS 127, 2000, p. 151. 
des formes de cette déesse, apaisées ou en voie d'apaisement. Sur la face interne de la porte, les protagonistes masculins du mythe font leur apparition. Dans les scènes couvrant les embrasures extérieure et intérieure ainsi que les deux représentations du tableau de l'embrasure, les divinités sont exclusivement masculines, exception faite de la figuration d’Isis dans la scène 107 qui se trouve justifiée par le caractère spécifique de l’offrande proposée, celle du Dodécaschène, qui est adressée à la divinité tutélaire du site. Or, nous avons vu que dans le passage de la porte et dans les scènes du linteau de la face interne, la reine était bien figurée, mais passive, derrière le souverain. La représentation double de la souveraine en façade ne répond pas seulement à une volonté d'associer à des divinités féminines un officiant du même sexe -sinon, pourquoi ne pas figurer de manière systématique la reine dans toutes les scènes des montants ?- mais entre dans un jeu d'opposition masculin / féminin que les décorateurs ont mis en avant en séparant les protagonistes du mythe.

L'examen de la situation des deux scènes sculptées au temple de Tôd ne fait que confirmer ce qui vient d'être exposé. La souveraine apparaît en façade présentant une offrande à des déesses liées à un contexte de naissance. Dans la salle des déesses, les divinités bénéficiaires des offrandes sont une fois encore exclusivement féminines. Les scènes inscrites sur les faces interne et externe de la porte montrent un personnel exclusivement féminin, exception faite des deux personnages masculins qui accompagnent la reine sur le linteau mais qui sont des génies associés à l’offrande de la reine. À l’inverse, les représentations inscrites sur les parois latérales de la salle voient disparaître ce personnel féminin qui est remplacé par le roi. On retrouve donc un jeu d'opposition construit sur le sexe des officiants et le positionnement des scènes avec une répartition territoriale plaçant la reine officiante dans une partie des scènes en façade et le roi dans toutes les représentations 'internes'.

\section{Des souveraines prêtresses ou simplement fiqurées comme officiantes?}

Les scènes sculptées au temple de Tôd, plus que les autres peut-être, posent réellement la question du rôle exact assumé par la souveraine. Est-elle figurée en qualité de prêtresse qui prend part de manière directe aux actions de ce personnel féminin et agit donc dans le cadre des cérémonies en liaison avec la salle des déesses, ou bien n’est-elle qu'une animatrice musicale ou vocale, activité bien connue pour le personnel féminin de la Maison Royale à 
partir de l'Ancien Empire ${ }^{72}$ ? S'agit-il de figurer une officiante réelle qui prend part aux cérémonies ou bien de traduire et de mettre en évidence, par le choix de la reine, une opposition masculin / féminin ?

Concernant le statut de prêtresse de la souveraine, les titulatures ne permettent pas de trancher. Jamais la reine ne porte une épithète qui la désigne comme prêtresse. La seule association, dans la scène est de Philae, de l'agitation des sistres à la menat, association souvent observée dans les représentations des prêtresses d'Hathor à l'Ancien Empire, n’est pas suffisante pour rattacher la souveraine à cette catégorie ${ }^{73}$. Même si la prêtrise féminine est bien attestée pour la période tardive, la question du rôle tenu par la reine et de son éventuelle implication dans la réalisation d’un rituel, voire même de sa conduite propre, reste posée.

Au temple de Tôd, cela pose également la question de la fonction réelle du personnel féminin dont la représentation, qui ne fait certainement pas figure d'unicum, reste toutefois extrêmement rare. Ce personnel féminin, dont on ne connaît finalement que le nom, `ky.wt, interviendrait dans la réalisation de cérémonie en rapport avec Tanent et Hathor. La nature même de ces cérémonies n'est pas précisée et l'appellation d’`ky.wt, qui s’apparente plus à un nom d'action que de fonction ${ }^{74}$, ne nous informe pas sur le rôle exact assumé par ce personnel. La scène sculptée dans l'embrasure de la porte montre la purification d'une personne féminine, purification qui lui octroie alors un statut de pureté suffisant pour entrer dans le temple et pratiquer une cérémonie. Ce statut de pureté, confirmé par la désignation de «pures » présente dans l'inscription 254, n'est toutefois pas synonyme de fonction de prêtrise. La féminisation du titre masculin $` k y . w$, ne permet pas de trancher la question. $k y . w t$ pourrait aussi bien désigner un personnel sacerdotal féminin, qu’un personnel laïc habilité à entrer dans le temple, car pur. Il a été démontré qu’à la période lagide les femmes pouvaient

\footnotetext{
${ }^{72}$ A.M. BLACKMAN, « On the position of women in the ancient egyptian hierarchy », JEA 7, 1921, p. 8-30 et plus particulièrement p. 20-25.

${ }^{73}$ À la Période Tardive les titres de prêtrise féminine sont rares, même si des femmes sont indéniablement associées aux cultes divins. Sur cette question, voir H.G. FISCHER, « Priesterin », LÄ IV, 1982, col. 1100-1105 ; A.M. BLACKMAN, « On the position of women in the ancient egyptian hierarchy », JEA 7, 1921, p. 8-30; W. OTто, Priester und Tempel im hellenistischer Ägypten I, Leipzig, Berlin, 1905, p. 92-93 ; L. TroY, Patterns of Queenships in ancient egyptian myth and history, Boreas 14, 1986, p. 73-91 et plus récemment Fr. CoLIN, « Les prêtresses indigènes dans l'Égypte hellénistique et romaine: une question à la croisée des sources grecques et égyptiennes », dans H. Melaerts, L. Mooren (éd.), Le rôle et le statut de la femme en Égypte hellénistique, romaine et byzantine. Actes du colloque international, Bruxelles-Leuven 27-29 Novembre 1997, StudHell 37, 2002, p. 41-122.

${ }^{74}$ Cf. supra, note 38 .
} 
bien être prêtresses et conduire, au même titre que les hommes, un rituel ${ }^{75}$. Rien n’empêche donc de voir dans les figures de Tôd des prêtresses.

On peut également s'interroger sur la fonction exacte de la reine dans cet ensemble. Alors que l'action du personnel féminin dans le cadre de cérémonies semble bien réel (mention dans les textes de leur action, figuration de tableaux les montrant en action), les tableaux du linteau dans lesquels apparaît la souveraine accompagnée des génies sont totalement sortis du réel et ne s'expliquent que par la volonté des décorateurs d'associer à ce contexte très emprunt de féminité une figure royale féminine. Ces représentations, tout comme celles provenant des temples de Philae et d'Elkab, ne sont donc en aucun cas les témoins d'une activité liturgique réelle de la souveraine même si, comme le notait avec justesse Fr. Colin, « (...) le roi était aux yeux des Égyptiens le prototype de tous les officiants du pays, la reine peut être regardée en quelque sorte comme la première prêtresse d'Égypte. ${ }^{76}$ ".

\section{L'implication réelle de la souveraine dans l'offrande}

Dans les tableaux montrant une reine comme seule officiante, la souveraine se présente face à la divinité et opère une action face à elle : agitation de sistres, offrande de pectoral ou encore présentation de myrrhe et de linges. Il est intéressant de noter que dans ces représentations, la reine ne semble pas être directement impliquée par l'offrande, si ce n'est par sa figuration. Ainsi, dans les deux scènes de Philae, le pronom suffixe =ỉ n'est jamais employé dans les titres de scènes pour faire parler la souveraine à la première personne alors que c’est le cas pour le souverain dans les scènes $n^{\circ} 71$ à $74^{77}$. De même, aucun échange n’est

\footnotetext{
${ }^{75}$ H.G. FISCHER, « Priesterin », LÄ IV, 1982, col. 1103 et Fr. COLIN, « Les prêtresses indigènes dans l'Égypte hellénistique et romaine: une question à la croisée des sources grecques et égyptiennes », dans H. Melaerts, L. Mooren (éd.), Le rôle et le statut de la femme en Égypte hellénistique, romaine et byzantine. Actes du colloque international, Bruxelles-Leuven 27-29 Novembre 1997, StudHell 37, 2002, p. 41-122. Après avoir redéfini les éléments permettant de caractériser la prêtrise à la période lagide (possession d'un titre, exécution concrète d'un rituel et exploitation des bénéfices d'un culte, possibilité de fonder ou d'intégrer une association religieuse) l'auteur en arrive à la conclusion, après l'examen des données égyptiennes et grecques, qu'il existait bien une prêtrise indigène dont on trouve d'ailleurs mention dans la procession couvrant le soubassement du mur extérieur du sanctuaire du temple d'Edfou où le titre de la prêtresse principale suit celle du grand prêtre pour chacun des nomes d'Égypte (Edfou I, p. 329-344).

${ }^{76}$ Fr. COLIN, « Les prêtresses indigènes dans l'Égypte hellénistique et romaine: une question à la croisée des sources grecques et égyptiennes », dans H. Melaerts, L. Mooren (éd.), Le rôle et le statut de la femme en Égypte hellénistique, romaine et byzantine. Actes du colloque international, Bruxelles-Leuven 27-29 Novembre 1997, StudHell 37, 2002, p. 116.

${ }^{77}$ La chose n’est pas certaine pour la scène $n^{\circ} 73$ (la paroi est endommagée à l'endroit où le titre de scène est inscrit) mais hautement probable. Dans les tableaux $n^{\circ} 75$ et 76 , comme pour les deux tableaux supérieurs, les pronoms suffixes disparaissent dans le titre de scène comme pour faire correspondre aux quatre scènes
} 
effectué entre la divinité et la reine. Les paroles prononcées en retour par les divinités ne voient jamais l'emploi du pronom suffixe deuxième personne du singulier féminin $=\underline{t}$ pour s’adresser directement à la reine alors que cela est systématique quant le roi officie (emploi du pronom $=k)^{78}$. Dans le texte correspondant aux paroles de Nekhbet c'est le pronom suffixe pluriel deuxième personne qui est employé (=t $\underline{t} n)$ niant de fait la présence unique de la reine et appliquant ce discours au couple royal dans son ensemble $\mathrm{e}^{79}$. Il est même un cas où la déesse ne s'adresse pas, comme à l'accoutumée, à l'officiant, mais à elle-même (annexe II ; paroles de Nephthys). À Philae, les inscriptions n’intègrent donc jamais la reine dans sa fonction d’officiante.

\section{Conclusion}

Il apparaît que les figurations doubles de souveraines officiantes ne sont spécifiques ni à un règne et une souveraine, ni à un type d'édifice, ni même à un espace particulier du temple même s’il est vrai que les tableaux sont toujours localisés à proximité de portes.

Dans deux des trois cas présentés (Elkab et Philae), les scènes apparaissent dans le contexte théologique du mythe de la Lointaine et les souveraines sont alors chargées, au même titre que les rois, d'effectuer des actions d'apaisement : agitation de sistres ou présentation du pectoral $b e b^{80}$. Le contexte est différent dans le cas des scènes du temple de Tôd car la reine apparaît liée à un contexte de naissance.

L'élément commun à ces trois cas de figure ne relève pas d'une théologie particulière, mais du contexte féminin très marqué avec une volonté évidente de la part des décorateurs de marquer une opposition territoriale entre masculin et féminin. Cela passe, dans ces trois cas, par l’intégration au programme décoratif de scènes montrant la reine en qualité d’officiante. On peut évidemment s’interroger sur la raison de la présence d'un nombre si faible

\footnotetext{
inférieures présentant le pronom, quatre tableaux supérieurs où il est absent. Il est impossible de se prononcer pour les quatre scènes du linteau car une cassure courant sur toute la largeur de la porte endommage les colonnes de textes.

${ }^{78}$ Voir les scènes nº65 à 68 et 71 à 76.

${ }^{79} \mathrm{Cl}$. Traunecker propose une autre explication à la présence de ce pronom pluriel. Notant l'existence de tableaux de linteaux dans lesquels la reine est figurée accompagnant le roi (par exemple sur la face sud de la porte du propylône de Montou à Karnak-Nord), il pense que, par jeu, un glissement de sa figure aurait été opéré du linteau vers les montants, expliquant de ce fait l'emploi du pronom pluriel.

${ }^{80}$ On remarquera que le texte 254 du temple de Tôd qui mentionne les officiantes pures rattache ces dernières à la confection de l’effigie de la déesse Oupeset, forme de la déesse Lointaine.
} 
d'attestions de ce type car il existe sans nul doute d'autres édifices et espaces décorés fortement emprunts de féminité. C’est le cas des sanctuaires des mammisis et nous avons mentionné les quatre représentations provenant du sanctuaire d’Erment. Les exemples sont toutefois peu nombreux par rapport à l'ensemble de la documentation attenante à ce type d’édifice et concentrés sur ce site ${ }^{81}$.

Il ne nous a pas été possible de trouver une ou des raisons complémentaires justifiant l'apparition de ces scènes spécifiquement à Philae, Tôd ou Elkab et il faut probablement admettre que les décisions de figurer ces doubles scènes ont été prises de manière locale et isolée. À compter du règne de Cléopâtre I, l'influence des souveraines est allée grandissante $^{82}$. Comme il a déjà été mentionné, la documentation hiéroglyphique qualifie, à partir du règne de Ptolémée VIII Evergète II-Cléopâtre II, les deux composantes régnantes de « pharaons » ce qui a peut-être facilité l'apparition de ces tableaux dans lesquels la souveraine est figurée seule, ce qui concerne aussi bien les représentations où la souveraine est placée en correspondance avec le roi que celles où sa figure est doublée. On s'étonnera tout de même du faible nombre de représentations de ce type ${ }^{83}$.

Dans le cas des représentations fonctionnant par paires, aucun attribut spécifique ou titre particulier de la souveraine n’a pu être identifié. Bien qu’officiantes par la représentation puisque seules figurées agissantes devant la divinité, ces souveraines restent indissociables d'une composante masculine avec, il est vrai, une indépendance plus grande pour Cléopâtre III et Cléopâtre VII dont les corégents ne sont pas directement mentionnés dans les représentations. Les reines ne sont jamais clairement désignées comme officiantes dans les textes et ne sont figurées qu'en qualité de composante féminine. Comme l'exemple de Tôd le montre clairement, la figuration de la reine n'a pas pour but de démontrer l'implication de

\footnotetext{
${ }^{81}$ Dans le sanctuaire premier du mammisi de Philae, Ol. Perdu a repéré la première attestation d'une souveraine ptolémaïque officiant seule, attestation qu'il date du règne de Ptolémée III Evergète I. Toutefois, la reine est placée en correspondance avec une représentation du souverain agissant devant la divinité. Il s'agit donc là d'un exemple de figuration scindée du couple royal (Ol. PERDU, «Souvenir d'une reine ptolémaïque officiant seule », ZÄS 127, 2000, p. 149 ; H. JUNKER, E. WINTER, Das Geburtshaus des Tempels der Isis in Philä, DÖAW Sonderband, 1965, p. 132. Une photographie de la scène est disponible dans E. VAssiLIKA, Ptolemaic Philae, OLA 34, 1989, pl. $15^{\mathrm{C}}$ ).

${ }^{82}$ M. MiNAS, « Cleopatra II and III: the queens of Ptolemy VI and VIII as guarantor of kingship and rivals of power », communication faite dans le cadre des journées internationales intitulées Ägypten zwischen innerem Zwist und äußerem Druck. Die Zeit Ptolemaios'VI. bis VIII. (Heidelberg, 17-19 septembre 2007, publication à paraître).

${ }^{83}$ Reste la question de la figuration de Bérénice II comme officiante dans le mammisi de Philae (H. JUNKER, E. WINTER, Das Geburtshaus des Tempels der Isis in Philä, DÖAW Sonderband, 1965, p. 132). Le rattachement de ces tableaux au règne de Ptolémée III Evergète I ne se fait que sur la base de l'étude des phases de décoration, les cartouches n’ayant pas été sculptés. Cette datation pose toutefois problème car les caractéristiques stylistiques de la souveraine ne sont pas comparables aux autres productions de ce règne sur le site (robe, coiffe). Divers indices permettent de proposer une identification de la souveraine avec Cléopâtre II.
} 
cette dernière dans une liturgie, mais d'associer, à ces contextes fortement emprunt de féminité, la seule femme susceptible d’être figurée en qualité d’officiante devant les divinités. 


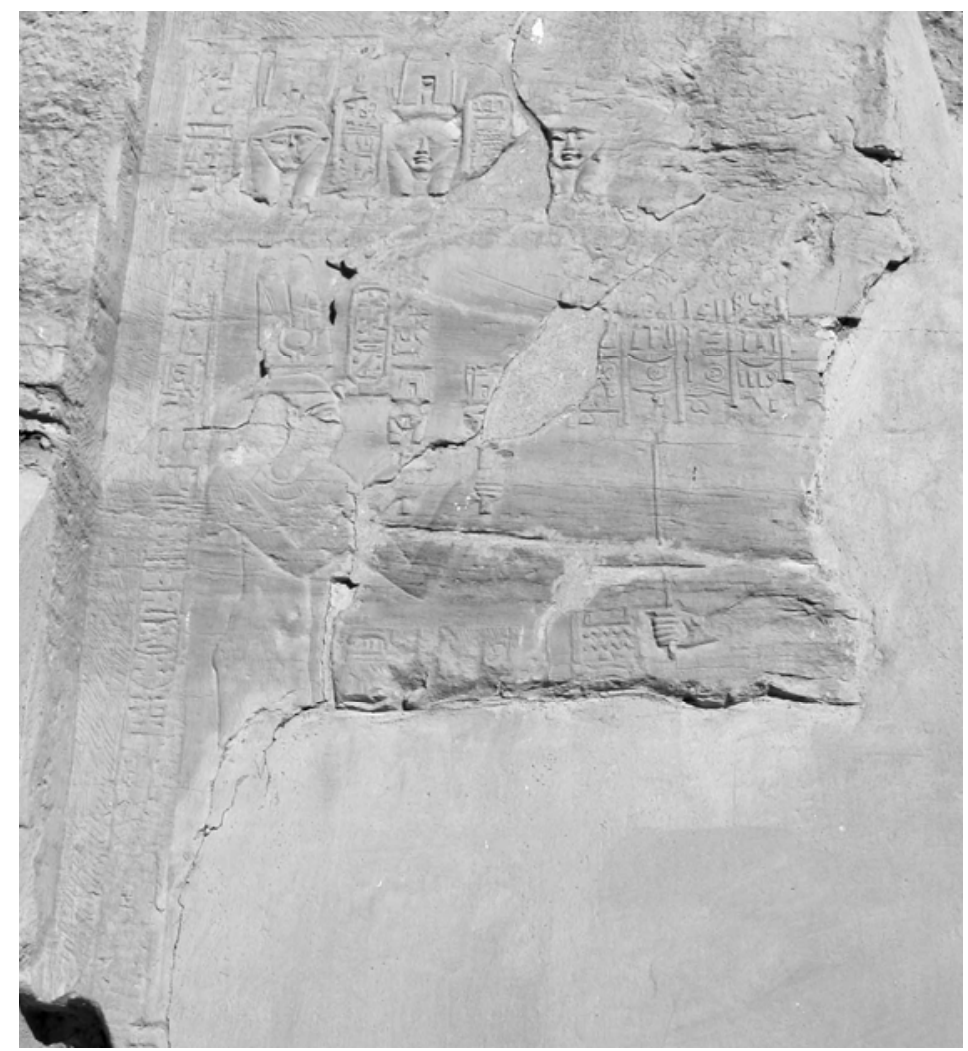

Fig. 1. Façade du spéos ptolémaïque d'Elkab, scène ouest (cliché L. Schmitt)

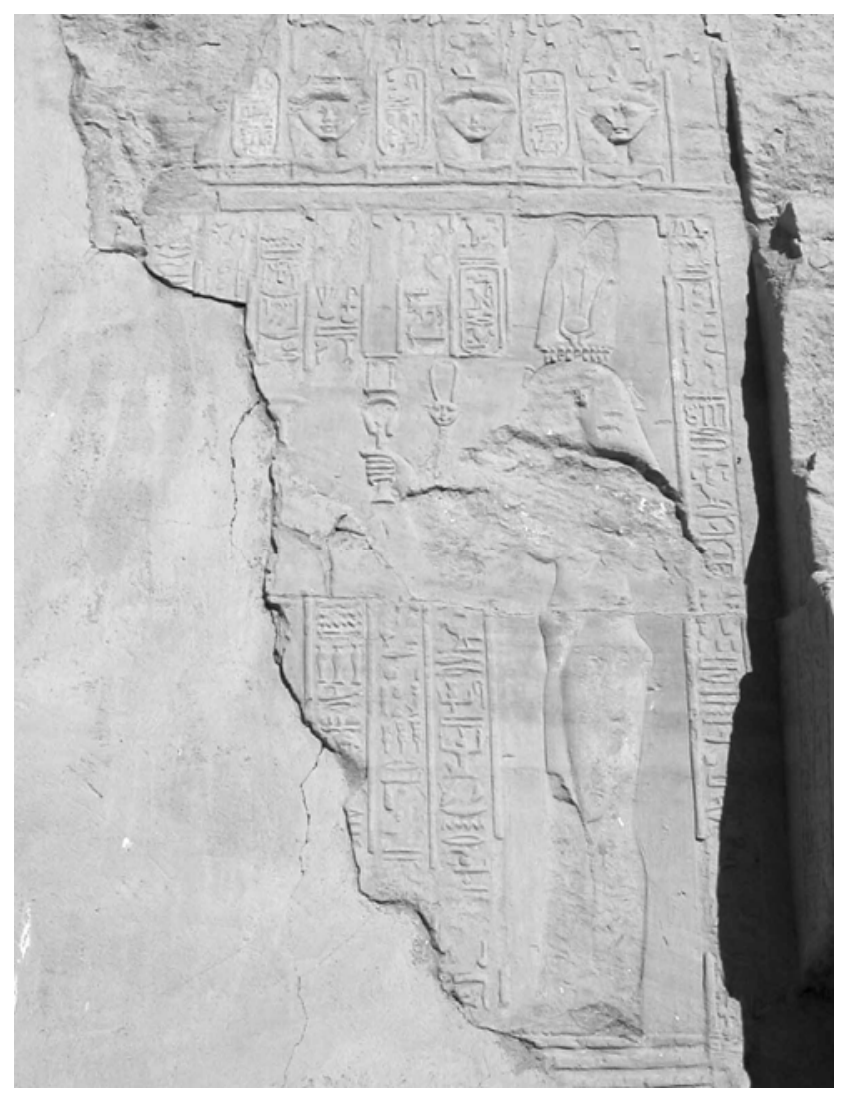

Fig. 2. Façade du spéos ptolémaïque d'Elkab, scène est (cliché L. Schmitt) 
Fig. 3. Récapitulatif de la décoration de la porte du second pylône de Philae (L. Martzolff)

Face sud

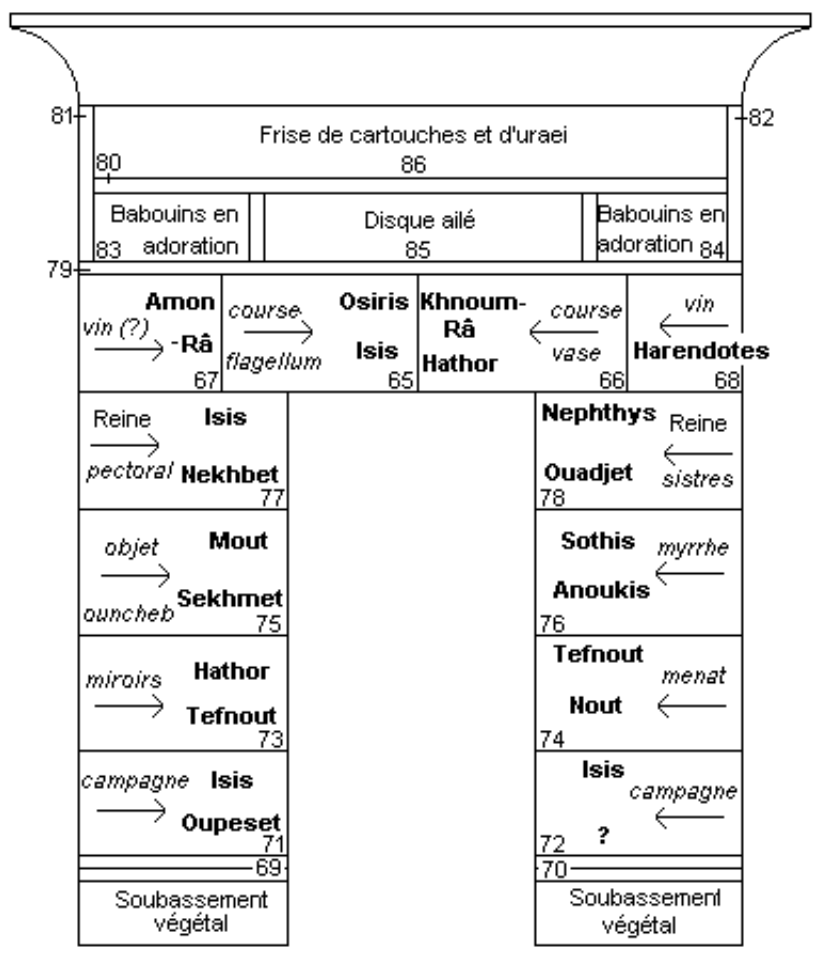

Embrasure ouest

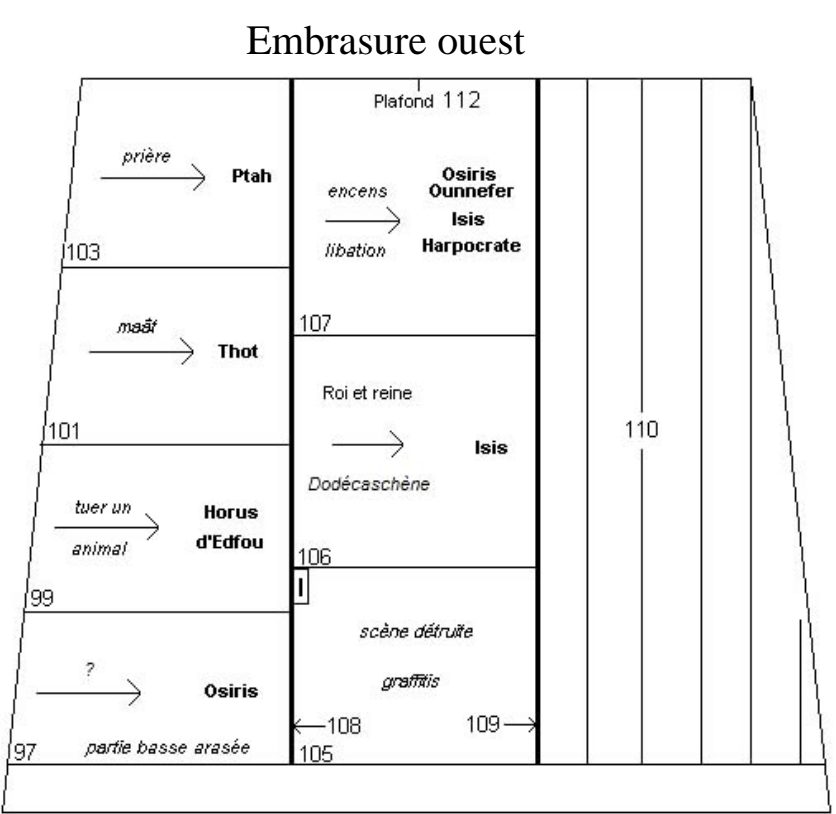

Face nord

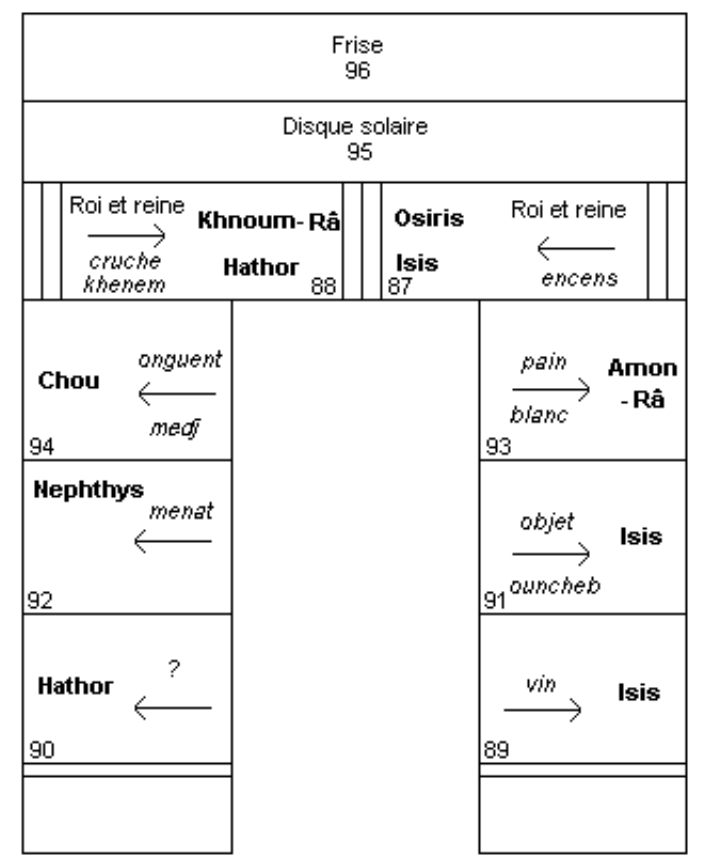

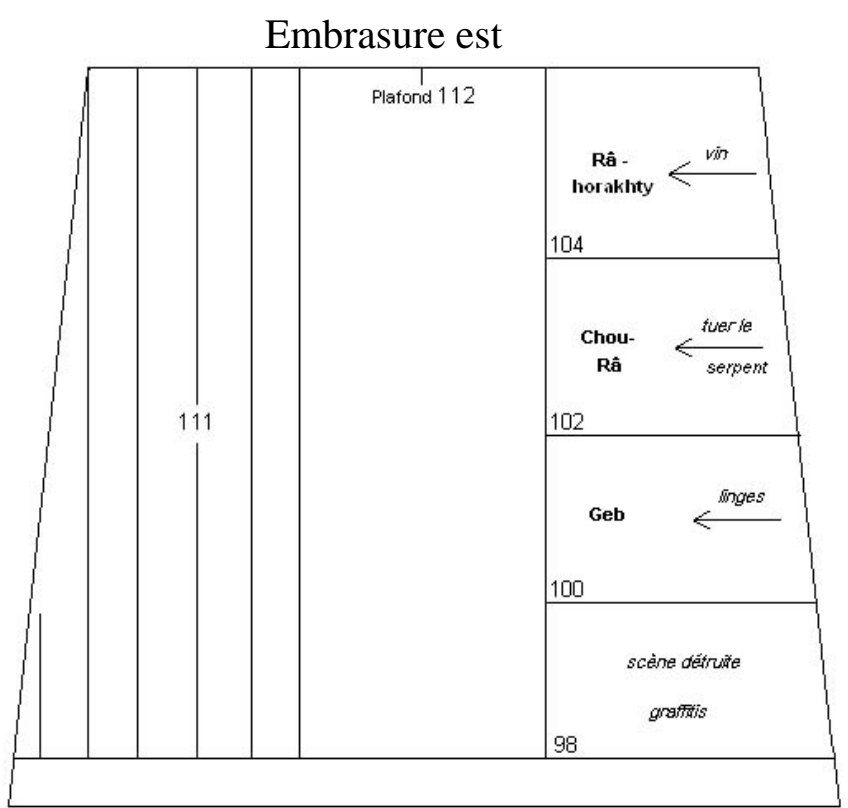




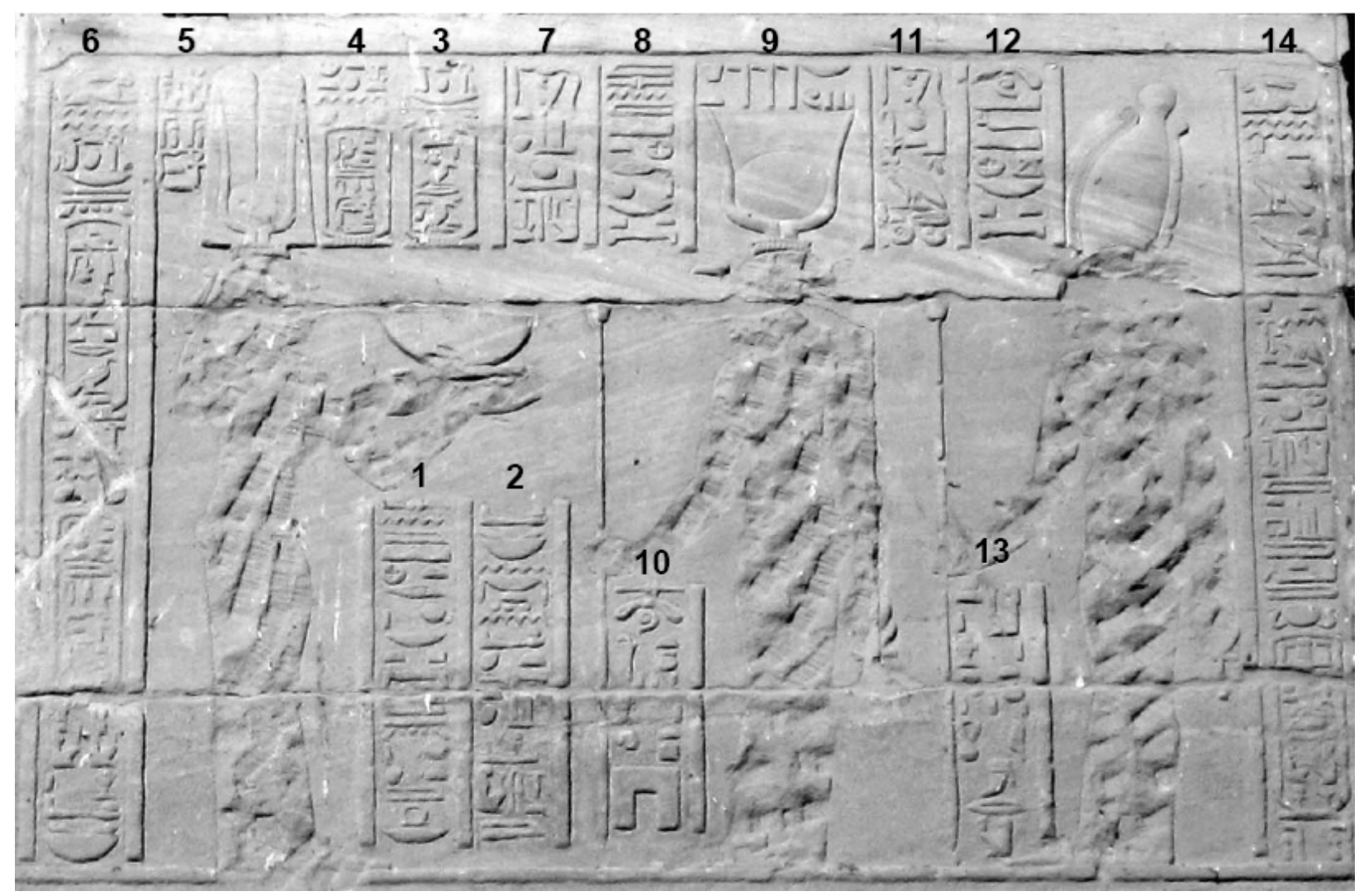

Fig. 4. Porte du second pylône de Philae, montant ouest (cliché C. Traunecker)

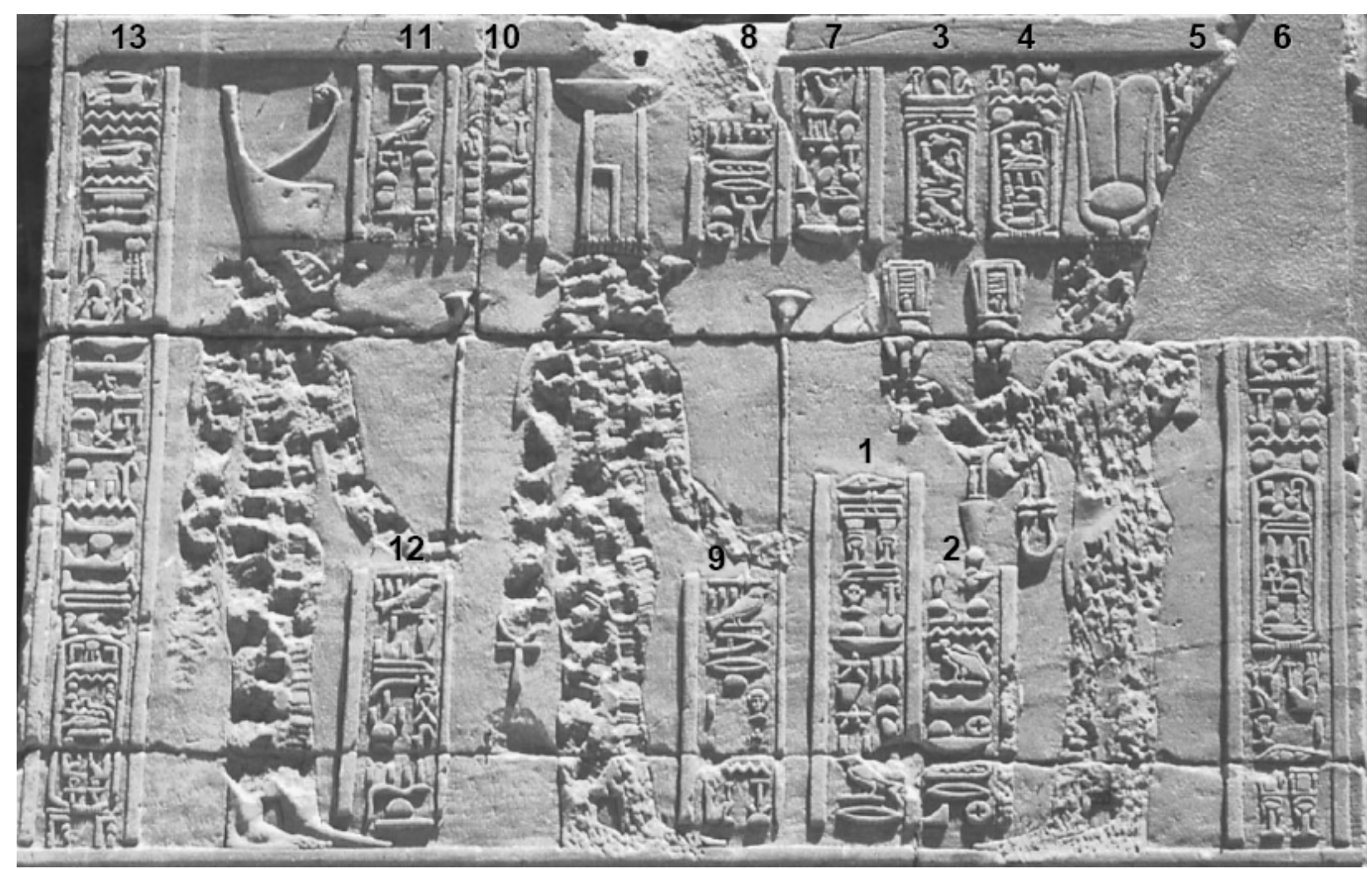

Fig. 5. Porte du second pylône de Philae, montant est (cliché L. Martzolff) 


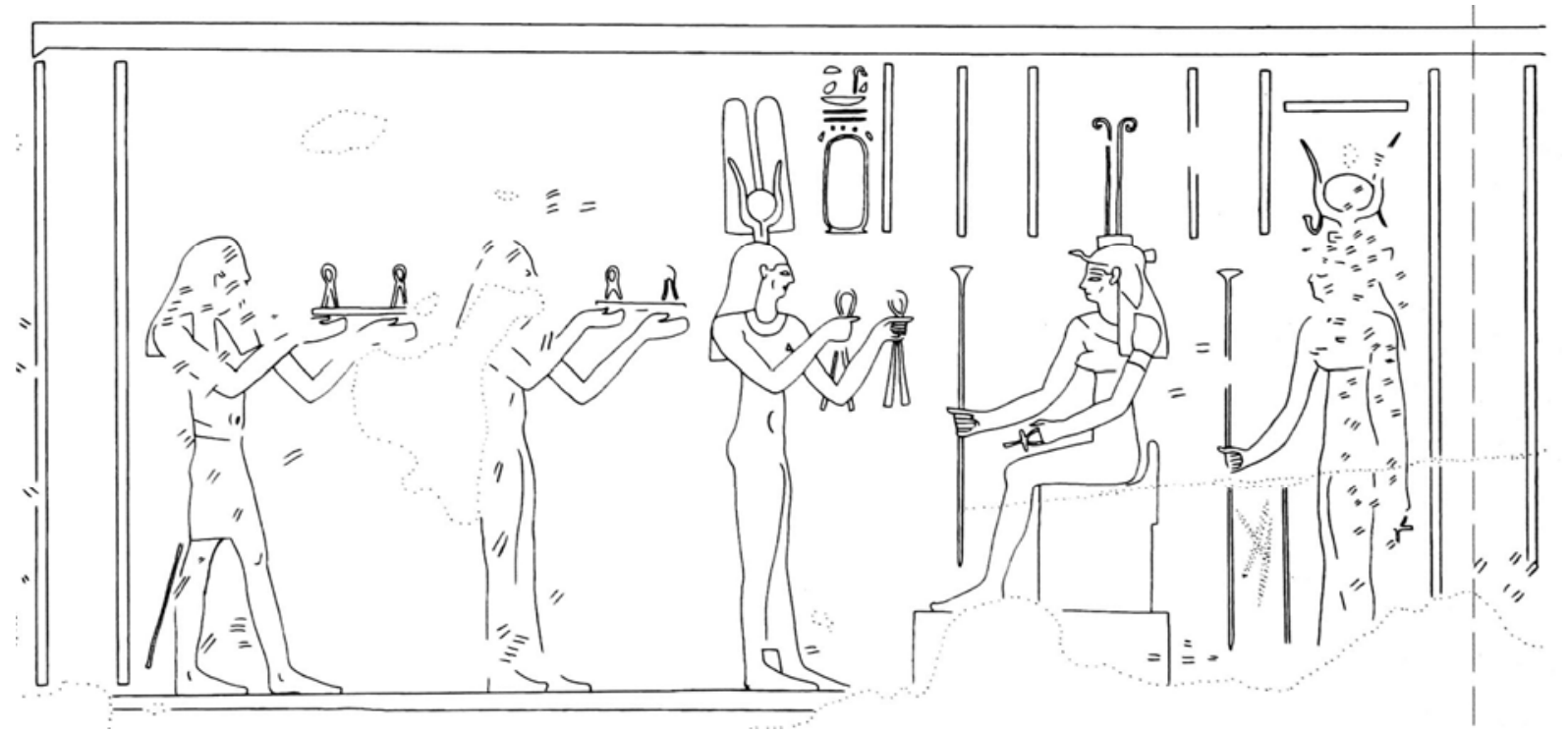

Fig. 6. Linteau de la porte de la salle des déesses du temple de Tôd, scène nord

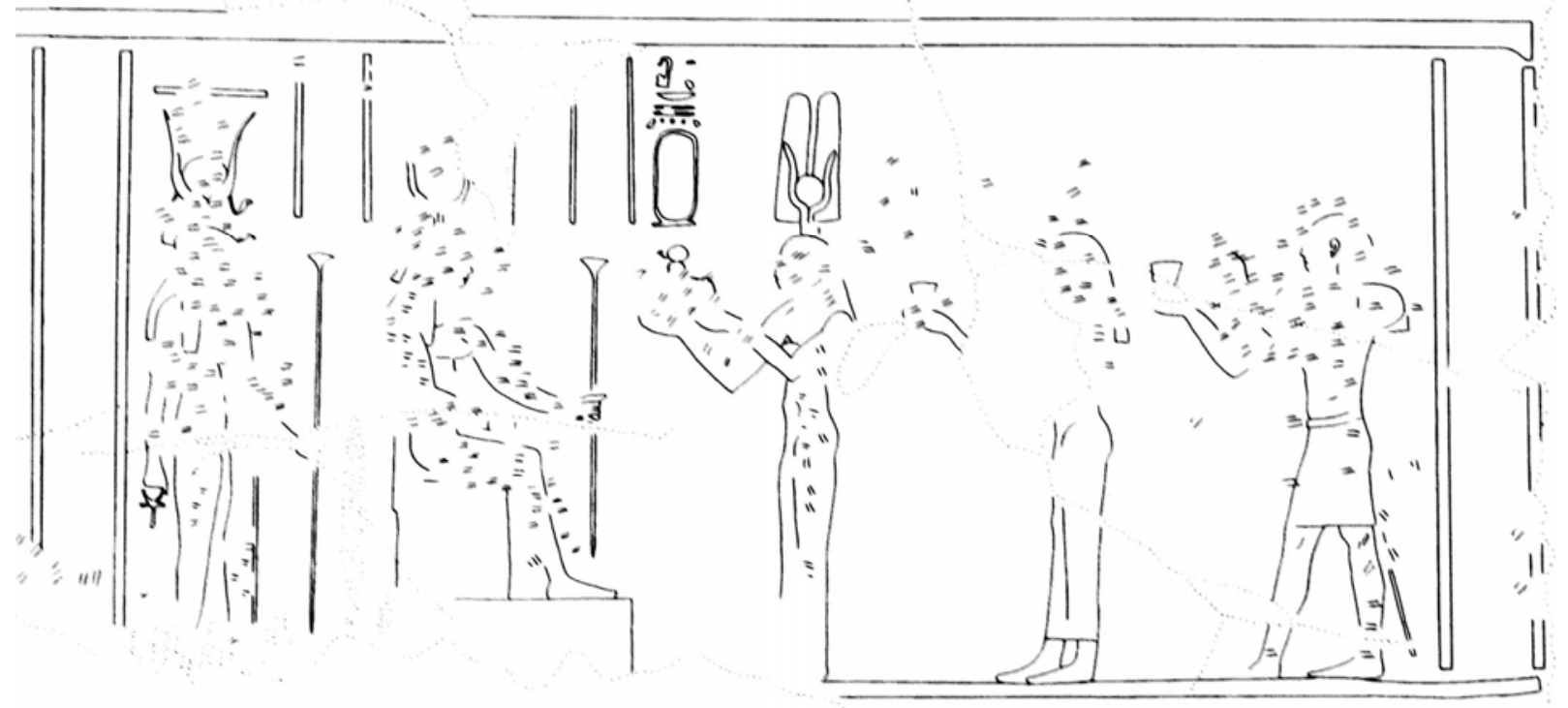

Fig. 7. Linteau de la porte de la salle des déesses du temple de Tôd, scène sud

(Fig. 6-7 : C. THIERs, Tôd. Les inscriptions du temple ptolémaïque et romain II. Textes et scènes $n^{\text {os }} 173-329$, FIFAO 18-2, 2003, n²46-247) 


\section{Annexe 1: inscriptions de la scène 77 de la porte du second pylône de Philae}

\section{$\underline{\text { Titre de scène }}^{84}$ :}

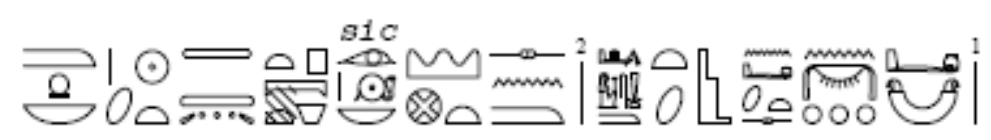

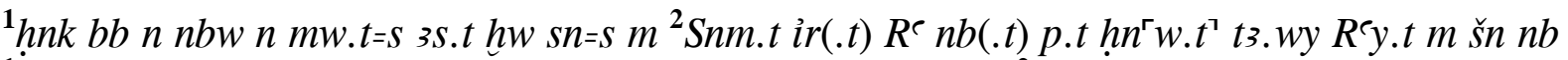
${ }^{1}$ Présenter le collier-beb ${ }^{85} \mathrm{~d}$ 'or à sa mère Isis, la protectrice de son frère ${ }^{2}$ dans Biggeh, l'œil de Râ, la maîtresse du ciel, la dame des deux terres, Râyt dans tout l'orbe (du disque).

\section{$\underline{\text { Nom et épithètes de la reine }}^{86}$ : $^{-}$}

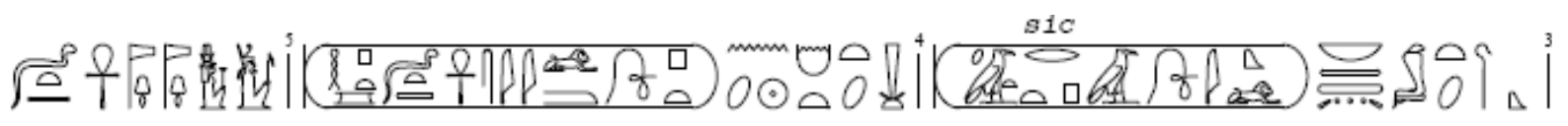

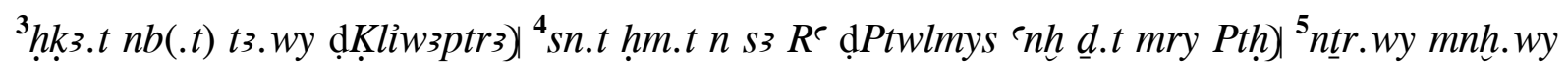
'nh d.t

${ }^{3}$ La souveraine, la maîtresse des deux terres ḍCléopâtre), ${ }^{4}$ la sœur et épouse du fils de Râ ḍPtolémée vivant à jamais, aimé de Ptah), ${ }^{5}$ les deux dieux Évergètes vivants à jamais.

\section{$\underline{\text { Colonne marqinale royale }}^{87}$ : $^{2}$}

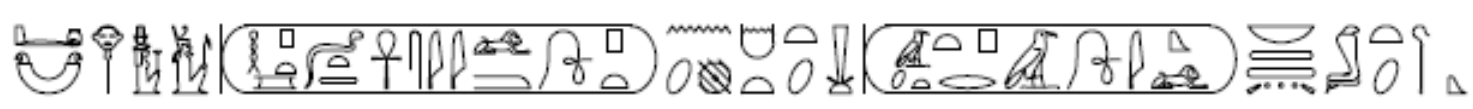

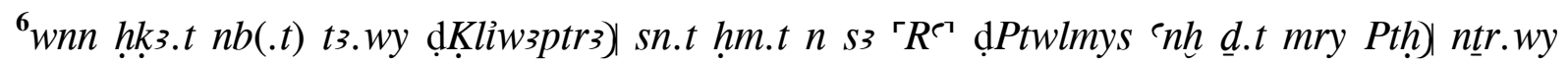
mnh.wy hr hnk bb

${ }^{6}$ La souveraine, la maîtresse des deux terres ḍCléopâtre), la sœur et épouse du fils de Râ ḍPtolémée vivant à jamais, aimé de Ptah), les deux dieux Évergètes ${ }^{88}$, offre le collier-beb.

\footnotetext{
${ }^{84}$ Pour une copie du titre de scène, voir Das Digitalisierte Zettelarchiv (DZA) n²5.852.780. La même fiche est répertoriée sous DZA n²2.873.990.

${ }^{85}$ Sur la lecture de ce terme, voir S. CAUVILLE, Le fonds hiéroglyphique au temps de Cléopâtre, Paris, 2001, p. 193.

${ }^{86} \mathrm{DZA} \mathrm{n}^{\circ} 28.883 .500$.

${ }^{87} \mathrm{DZA} \mathrm{n}^{\circ} 22.874 .000$.

${ }^{88}$ Il est intéressant de noter que les graphies du groupe $n \underline{t} r$.wy $m n h$.wy varient, dans les deux scènes, en fonction

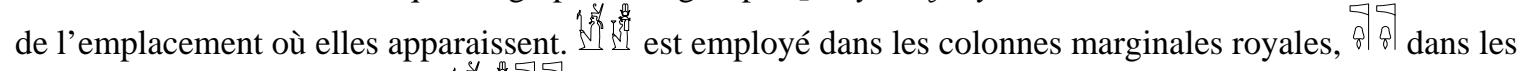

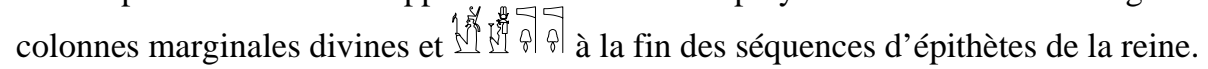




\section{Épithètes et paroles d'Isis ${ }^{89}$ :}

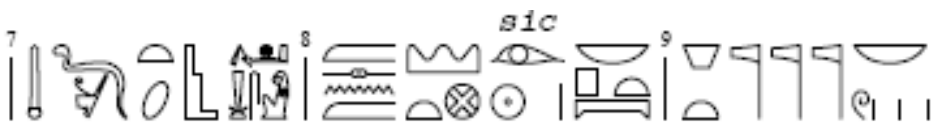

${ }^{7} d d m d w$ in $3 s . t^{90} h w$ sn=s ${ }^{8} m$ Snmt ir $(. t) R^{e}{ }^{9} n b(. t)$ p.t hnnw.t ntr.w nb.w

${ }^{7}$ Paroles prononcées par Isis qui protège son frère ${ }^{\mathbf{8}}$ dans Biggeh, l'œil de Râ, la maîtresse du ciel, ${ }^{9}$ la dame de tous les dieux.

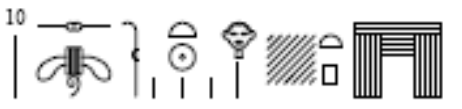

${ }_{S 3 w(=i)}^{10} r p . w t h r[1 / 2$ cadrat $] t p$

${ }^{10}$ Je prolonge les années sur le trône ${ }^{91}$.

\section{Épithètes et paroles de Nekhbet ${ }^{92}$ :}

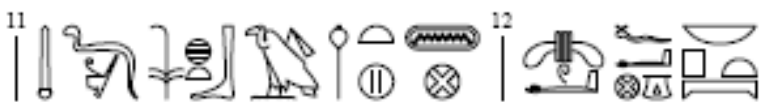

${ }^{11} d d m d w$ in Nhbt had.t $N h n{ }^{12} 3 w(. t)-{ }^{-} F e g ~ n b(. t) p . t$

${ }^{11}$ Paroles prononcées par Nekhbet, la blanche de Nekhen ${ }^{12}$ au bras étendu, celle de Fâg, la maîtresse du ciel.

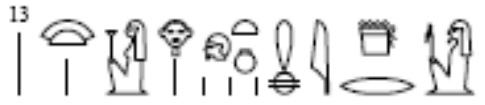

${ }^{13} h^{e}=i$ hr tp=tn mi Dr

${ }^{13}$ J'apparais sur votre ${ }^{93}$ tête comme (sur celle de) Djer ${ }^{94}$.

\footnotetext{
${ }^{89} \mathrm{DZA}{ }^{\circ} 28.883 .500$.
}

${ }^{90}$ La direction des signes dans le cadrat comprenant le nom de la déesse a été totalement inversée de manière à faire correspondre l'orientation de la reine avec celle des hiéroglyphes servant à écrire le nom de la déesse. Les inversions de ce type ne sont pas rares dans les textes du second pylône de Philae et concernent majoritairement le nom de la déesse Isis (scènes 65, 71, 72, 106 et 107) sans pour autant qu’une règle ne puisse être énoncée. Ce phénomène, qui est également attesté pour Nephthys (scène 78) et Osiris (scènes 65 et 97), est indépendant du sexe de l'officiant. L'inversion ne peut donc s'expliquer par la volonté de mettre en correspondance une divinité et un officiant de même sexe.

\footnotetext{
${ }^{91}$ Le premier signe appartenant au terme n’est pas reconnaissable sur la paroi. La traduction du terme par « trône » est proposée par le rédacteur de la fiche et convient parfaitement au contexte.

${ }^{92}$ DZA n³1.679.400.

${ }^{93}$ Le pluriel ne peut s’appliquer qu’aux deux souverains, Cléopâtre II et Ptolémée VIII Evergète II.

${ }^{94} \mathrm{Il}$ s'agit du nom du dieu solaire à Philae $\left(\mathrm{Wb} \mathrm{V}, 595^{13}\right)$.
} 


\section{Colonne marqinale divine $^{95}$ : $^{2}$}

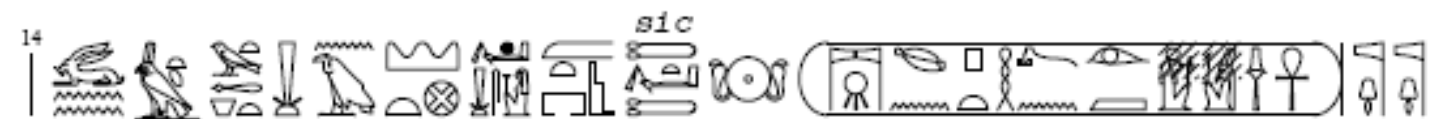

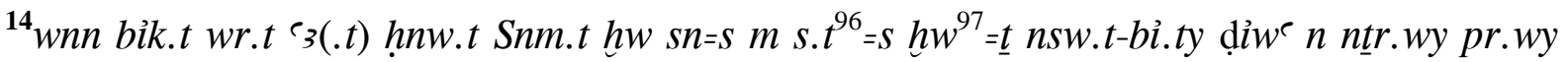

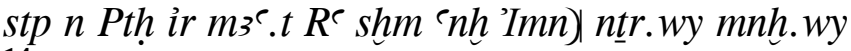

${ }^{14}$ Le très grand faucon femelle, la dame de Biggeh qui protège son frère dans sa place, puisses-tu protéger le roi de Haute et Basse Égypte ḍl'héritier des dieux Épiphanes élu de Ptah, qui accomplit la maât de Râ, l'image vivante d'Amon), les deux dieux Évergètes.

\footnotetext{
${ }^{95}$ DZA n²2.837.970.
}

${ }^{96}$ L'orientation du cadrat a été changée ce qui tient sans nul doute à la présence du signe $\int$ utilisé pour écrire le nom de la déesse Isis. Sur les questions d'inversion, cf. supra, note 89.

${ }^{97}$ Le scribe a semble-t-il inscrit un $t$ à la place du $h$. 


\section{Annexe 2 : inscriptions de la scène 78 de la porte du second pylône de Philae}

Titre de la scène :

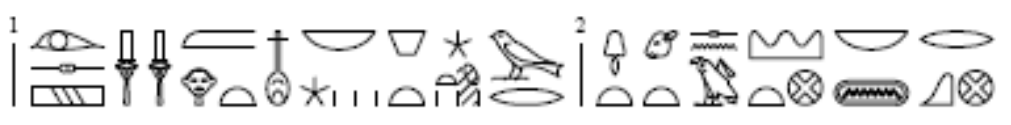

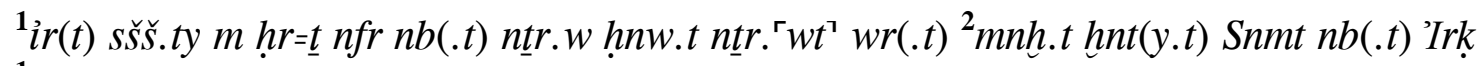

${ }^{1}$ Agiter les deux sistres devant ton beau visage, la maîtresse des dieux, la dame des déesses, la grande, ${ }^{2}$ la vénérable qui préside à Biggeh, la maîtresse de Philae.

\section{$\underline{\text { Nom et épithètes de la reine }}^{98}$ : $^{-}$}

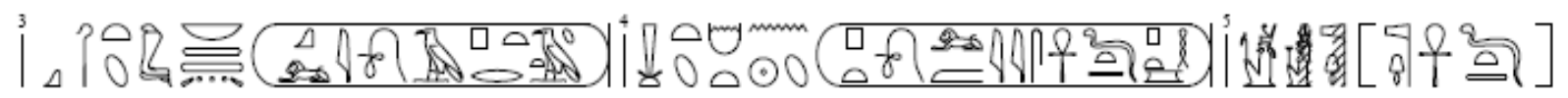

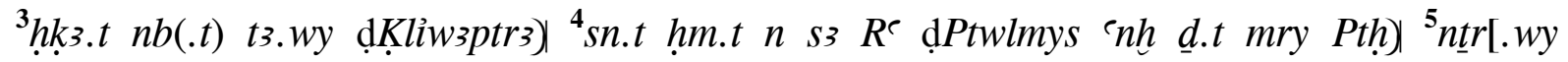
mnh.wy enh d. $\underline{\text { t] }]}$

${ }^{3}$ La souveraine, la maîtresse des deux terres ḍCléopâtre), ${ }^{4}$ la sœur et épouse du fils de Râ ḍPtolémée vivant à jamais, aimé de Ptah), ${ }^{5}$ les [deux] die[ux Évergètes vivants à jamais ${ }^{99}$.

\section{Colonne marqinale royale :}

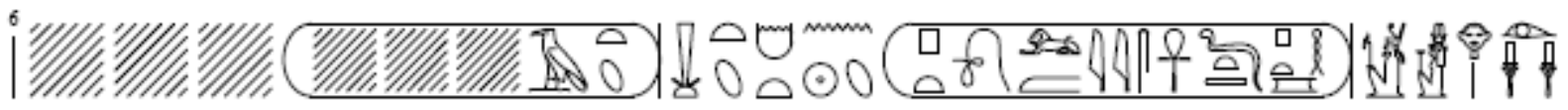

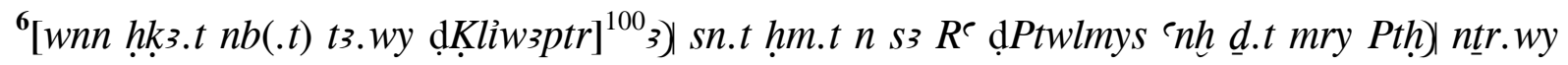
mnh.wy hr ir ššs.ty

${ }^{6}$ [La souveraine, la maîtresse des deux terres ḍCléopâtr]e), la sœur et épouse du fils de Râ ḍPtolémée vivant à jamais, aimé de Ptah), les deux dieux Évergètes, agite les deux sistres.

\section{$\underline{\text { Épithètes et paroles de Nephthys }}^{101}$ :}

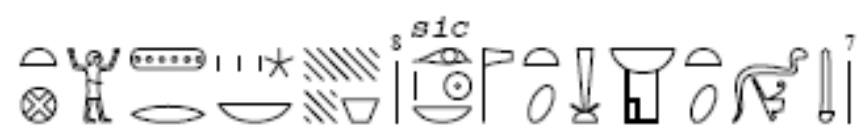

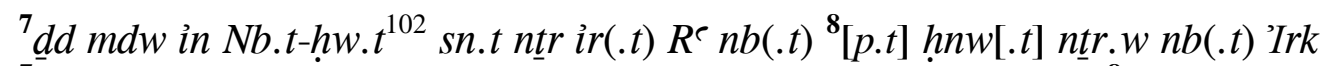

${ }^{7}$ Paroles prononcées par Nephthys, la sœur du dieu, l'œil de Râ, la maîtresse ${ }^{\mathbf{8}}$ du [ciel ${ }^{103}$ ], la dame des dieux, la maîtresse de Philae.

\footnotetext{
${ }^{98} \mathrm{DZA} \mathrm{n}^{\circ} 28.786 .780$.

${ }^{99}$ La restitution se fait sur la base de la séquence de noms et épithètes de la scène correspondante.

${ }^{100}$ Le texte en lacune est restitué à partir de la scène correspondante.

${ }^{101}$ DZA n²9.062.630.

${ }^{102}$ Cf. supra, note 89.
} 


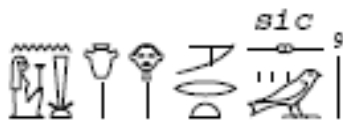

${ }^{9} s w r(=i) m r w . t$ hr ỉb $s n=\imath$

$\mathbf{9}_{\text {Je fais croître l'amour dans }}{ }^{104}$ le cœur de mon frère.

\section{Épithètes et paroles de Ouadjiit $^{105}$ :}

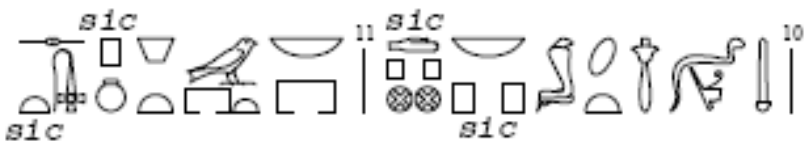

${ }^{10} d d m d w$ in $W 3$ d d.t $n b(. t) P D p{ }^{11} n b(. t)$ Pr-wr hnnw.t Pr-nsr

${ }^{10}$ Paroles prononcées par Ouadjit, la maîtresse de Pe et de Dep, ${ }^{11}$ la maîtresse du Per-our, la dame du Per-neser.

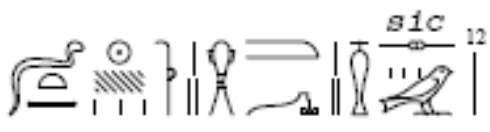

${ }^{12} s w r(=i) h s . w t m$ stp-s3.w rnp.wt [1/2 cadrat] d.t

${ }^{12}$ Je grandis les louanges dans les palais ainsi que les années $\left[1 / 2\right.$ cadrat $\left.^{106}\right]$ à jamais.

\section{Colonne marginale divine $^{107}$ :}

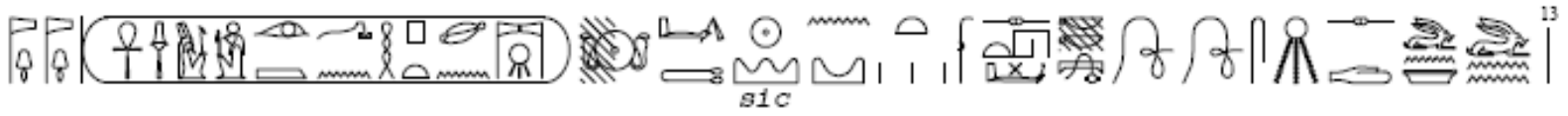

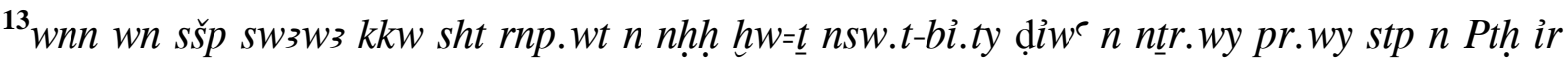
$m 3^{\complement} . t R^{\top}$ shm 'nh 'Imn)| ntrr.wy mnh.wy

${ }^{13}$ Celle qui amène la lumière, qui éloigne l'obscurité, qui sehet ${ }^{108}$ les années de l'éternité-neheh, puisses-tu protéger le roi de Haute et Basse Égypte ḍl'héritier des dieux Épiphanes élu de Ptah, qui accomplit la maât de Râ, l'image vivante d'Amon), les deux dieux Évergètes.

\footnotetext{
${ }^{103}$ Les épithètes de la déesse Isis de la scène correspondante permettent de compléter le cadrat pour lire $\square \odot$, « la maîtresse du ciel, la dame des dieux ».

${ }^{104}$ Sur le sens de la préposition, voir H. JunKER, Grammatik der Denderatexte, Leipzig, 1906, § $192^{4}$.

${ }^{105}$ DZA n'29.062.760.

${ }^{106}$ Peut-être faut-il voir dans cette lacune une graphie du pronom suffixe =ț et lire vos années (de règne) ?

${ }^{107}$ DZA n $^{\circ} 22.368 .140$ ou DZA n²8.786.780.

${ }^{108}$ Le sens de ce verbe, intégré à cette expression qualifiant Nephthys (Wb IV, 2095), n’a pu être précisé.
} 


\section{English summary}

In the graeco-roman temples, the scenes in which the queen is officiating alone in front of one or several divinities are limited since only forty or so cases have been recorded by O. Perdu in 2000. In a very large majority of cases, the scene where the queen is appearing is put in correspondence with another one where a king is acting. The queen being the equal of the king, this construction is putting the stress on the two parts of the royal couple, the male and female one. However, two scenes carved in frontage of the hemispeos of Elkab must be isolated. There, the two scenes showing the queen are associated on both sides of the door. Being first considered as an exception, this situation is also observed in the temples of Philae and Tod. This work proposes to present and study these four new scenes. The examination of the theological context of those representations proves that the figuration of the queen is not due to her implication in the government but to the feminine aspect of the theology developed. 